\title{
Epigenetic Regulation of Sensory Axon Regeneration after Spinal Cord Injury
}

\author{
Mattéa J. Finelli, ${ }^{1 *}$ Jamie K. Wong, ${ }^{1 *}$ and Hongyan Zou ${ }^{1,2}$ \\ ${ }^{1}$ Fishberg Department of Neuroscience and ${ }^{2}$ Department of Neurosurgery, Friedman Brain Institute, Icahn School of Medicine at Mount Sinai, New York, \\ New York 10029
}

\begin{abstract}
Axon regeneration is hindered by a decline of intrinsic axon growth capability in mature neurons. Reversing this decline is associated with the induction of a large repertoire of regeneration-associated genes (RAGs), but the underlying regulatory mechanisms of the transcriptional changes are largely unknown. Here, we establish a correlation between diminished axon growth potential and histone 4 (H4) hypoacetylation. When neurons are triggered into a growth state, as in the conditioning lesion paradigm, $\mathrm{H} 4$ acetylation is restored, and RAG transcription is initiated. We have identified a set of target genes of Smad1, a proregenerative transcription factor, in conditioned DRG neurons. We also show that, during the epigenetic reprogramming process, histone-modifying enzymes work together with Smad1 to facilitate transcriptional regulation of RAGs. Importantly, targeted pharmacological modulation of the activity of histone-modifying enzymes, such as histone deacetylases, leads to induction of multiple RAGs and promotion of sensory axon regeneration in a mouse model of spinal cord injury. Our findings suggest epigenetic modulation as a potential therapeutic strategy to enhance axon regeneration.
\end{abstract}

Key words: axon regeneration; conditioning lesion; DRG neurons; epigenetic regulation; Smad1; spinal cord injury

\section{Introduction}

Mature neurons of the mammalian CNS regenerate minimally. After spinal cord injury (SCI), connections between brain and spinal cord are severed, resulting in loss of motor and sensory functions below the lesion. Failure of axonal regeneration is attributed to a growth-inhibiting environment at the injury site (Schwab and Bartholdi, 1996; Filbin, 2003; Liu et al., 2010) and an age-dependent decline in the intrinsic axon growth potential (Goldberg, 2003). Blocking extracellular inhibitors enables only limited axonal regeneration (Case and Tessier-Lavigne, 2005; Harel and Strittmatter, 2006; Lee et al., 2010); thus, identifying an approach to rekindle the innate growth potential remains critical.

As neurons mature, genes mediating axon growth undergo transcriptional changes, and these changes are not reversed after injury, thus constituting a roadblock for axon regeneration. The molecular nature of the transcriptional regulation of proregenerative genes is not understood, although epigenetic modifications may play a role (Bird, 2007). One of the best-studied epigenetic regulations is the reversible acetylation and deacetylation of histone lysine residues (Kouzarides, 2007). Histone acetyltransferases (HATs) add acetyl groups to lysines, leading to

Received Feb. 4, 2013; revised Nov. 5, 2013; accepted Nov. 6, 2013.

Author contributions: M.J.F. and H.Z. designed research; M.J.F., J.K.W., and H.Z. performed research; M.J.F., J.K.W., and H.Z. analyzed data; M.J.F., J.K.W., and H.Z. wrote the paper.

This work was supported by the Whitehall, Craig H. Neilsen, Irma T. Hirschl/Monique Weill-Caulier Foundations, and National Institute of Neurological Disorders and Stroke NS073596 to H.Z.

The authors declare no competing financial interests.

${ }^{*}$ M.J.F. and J.K.W. contributed equally to this work.

Correspondence should be addressed to Dr. Hongyan Zou, Friedman Brain Institute, Icahn School of Medicine at

Mount Sinai, 1425 Madison Avenue, New York, NY 10029. E-mail: hongyan.zou@mssm.edu.

DOI:10.1523/JNEUROSCI.0589-13.2013

Copyright $\odot 2013$ the authors $\quad 0270-6474 / 13 / 3319664-13 \$ 15.00 / 0$ a more open chromatin. Histone deacetylases (HDACs) remove the acetyl groups, resulting in a more condensed chromatin that is usually associated with gene silencing. In the CNS, histone acetylation plays an important role for learning and memory, neuroplasticity, and neurodegeneration (Peleg, 2010; Konsoula and Barile, 2012). Recent studies have also implicated epigenetic mechanisms in axon regeneration (Trakhtenberg and Goldberg, 2012). For instance, the folate pathway mediates CNS axon regeneration through global and gene-specific DNA methylation (Iskandar et al., 2010). In postnatal cerebellar granule neuron cultures, trichostatin-A (TSA), a broad-spectrum inhibitor of Class I/II HDACs (HDACi), can induce histone H3K9/14 hyperacetylation, enhance expression of the axon regeneration marker GAP43, and increase neurite growth on both permissive and inhibitory substrates (Tedeschi et al., 2009; Gaub et al., 2010). Valproic acid, a Class I-selective HDACi, improves motor function recovery in animal models of SCI (Lv et al., 2012). In an optic nerve crush model, TSA increases survival of retinal ganglionic cells but has no effect on axon regeneration, whereas overexpression of p300, a HAT, promotes axon regeneration, but not RGC survival (Gaub et al., 2011). Together, the precise role of epigenetic modulation in axon regeneration may be cell type-specific and context-dependent.

We hypothesized that epigenetic mechanisms may play a role in the diminished axon growth potential in adult sensory neurons. To test this hypothesis, we took advantage of the unique regenerative capability of adult sensory neurons in the DRG in the conditioning lesion paradigm. DRG neurons project one peripheral axonal branch to innervate sensory targets and one central axonal branch to relay sensory information to the CNS. Remarkably, the central branch that is normally refractory to regeneration can be triggered into a growth state if the peripheral 
branch is axotomized first: the so-called conditioning lesion (Richardson and Issa, 1984; Neumann and Woolf, 1999) (see Fig. $1 A)$. The conditioning effect involves the transcription of many regeneration-associated genes (RAGs) (Skene, 1989; Bosse et al., 2001); however, the underlying transcriptional mechanisms remain poorly understood. Our previous studies have identified a critical role for Smad1, a conserved transcription factor (TF) downstream of BMP signaling, during axon regeneration (Zou et al., 2009; Parikh et al., 2011). Loss of Smad1 reduces axon growth potential, whereas activating Smad1 enhances sensory axon regeneration after SCI. Smad1 is capable of collaborating with histone-modifying enzymes to regulate gene expression (Pearson et al., 1999; Kim and Lassar, 2003). However, downstream targets of Smad1 in DRG neurons have not been identified, and how phosphorylated Smad1 (pSmad1) exerts transcriptional regulation is not fully understood.

Here, we demonstrate a correlation between histone acetylation and intrinsic axon growth capacity in adult DRG neurons. We identify a transcriptional complex, consisting of at least pSmad 1 and histone-modifying enzymes, that participates in the restoration of promoter histone acetylation and induction of a subset of early RAGs. Importantly, targeted pharmacological modulation of the activity of histone deacetylases in vivo leads to histone $\mathrm{H} 4$ hyperacetylation, induction of multiple RAGs, and promotion of sensory axon regeneration after SCI.

\section{Materials and Methods}

Mouse strains. All surgeries were performed on 6- to 8-week-old mice in accordance with the guidelines and protocols approved by the Institutional Animal Care and Use Committee at the Mount Sinai School of Medicine. For in vivo spinal cord injury studies, C57BL/6 female mice were used. For all other experiments, CD1 mice were used. Smad1 $1^{\text {flox/flox }}$ mice (Huang et al., 2002) and Wnt1-Cre line (Danielian et al., 1998) were obtained from The Jackson Laboratory. Smad1 heterozygous germline deletion $\left(\operatorname{Smad1}^{+/-}\right)$and conditional knock-out (cKO, Smad1 $1^{f l /-}$; Wnt1-Cre) were generated in our laboratory.

C5 dorsal column lesion, peripheral axotomy, and analysis of axon regeneration. For the dorsal column lesion, a C5 laminectomy was performed and ascending sensory fibers were transected using iris microscissors (Fine Science Tools) to a depth of $0.8 \mathrm{~mm}$. After the injury, mice received a daily subcutaneous injection of MS-275 (Selleckchem, $12.5 \mathrm{mg} / \mathrm{kg}$ ), TSA (Enzo, $10 \mathrm{mg} / \mathrm{kg})$, or vehicle (1:10 DMSO/saline) for 4 consecutive days. Axon regeneration was assayed at 2 weeks after dorsal column lesion by labeling the ascending sensory axons in the fasciculus gracilis, as previously described (Parikh et al., 2011). Briefly, Dextran-Texas Red (DexTR, Invitrogen) tracer was injected into the right sciatic nerve. Three days later, mice were perfused intracardially with 4\% PFA (Sigma) in $0.1 \mathrm{M}$ phosphate buffer, and the spinal cord segments close to C5 lesion site were cryoprotected, embedded, and sectioned at $25 \mu \mathrm{m}$ thickness in sagittal orientation. In each animal, all labeled axons were counted in three consecutive sections closest to the midline where labeling was most abundant. Axon index was calculated based on the ratio of the number of DexTR $^{+}$axons at a specific location relative to the axon number at the most caudal location. Lesion scars were delineated by a combination of GFAP or chondroitin sulfate proteoglycans (CSPG) immunostaining in conjunction with DAPI nuclear counterstaining, which clearly demonstrated a gradient of increased cell density from the lesion center to the boundary. The glial scar was visualized not only by increased GFAP signal intensity, but also by the disorganization of $\mathrm{GFAP}^{+}$glia that distinguishes the boundaries of the scar.

For the peripheral conditioning lesion, the right sciatic nerve was transected at mid-thigh level. Ipsilateral lumbar 4, 5, and 6 (L4-L6) DRGs, the three main lumbar DRGs that contribute to the sciatic nerve, were compared with contralateral naive L4-L6 DRGs. It is noteworthy that not all sensory neurons in the L4-L6 DRGs experience peripheral axotomy after a sciatic nerve transection, as some of the DRG neurons proj- ect to the dorsal ramus of spinal nerves to innervate local tissues or the femoral nerve in the lumbar plexus, as in the case of L4 DRGs. For immunostaining, L5 DRGs were used because a higher percentage of the L5 neurons contribute to the sciatic nerve.

In vivo axon regeneration study and quantification were performed in a blinded fashion. Ten C57BL/6 mice were used for each experiment with 5 mice for each cohort. The MS-275 experiment was replicated with another cohort, and data were pooled together for final analysis.

Cell culture. Mouse Neuro-2A cells were maintained in DMEM (Invitrogen) supplemented with $10 \%$ FBS (Lonza) and $100 \mathrm{U} / \mathrm{ml}$ penicillinstreptomycin (Invitrogen). Neuro-2A cells were treated with BMP4 (50 ng/ ml, R\&D Systems) for $8 \mathrm{~h}$, MS-275 (3.3 $\mu \mathrm{M})$ for $48 \mathrm{~h}$, or transfected with siRNA for $48 \mathrm{~h}$ (DharmaFECT2, Smad1 siRNA or control siRNA from Dharmacon, $100 \mathrm{~nm}$ ).

$D R G$ cultures and neurite outgrowth assay. DRGs from adult mice were dissected and dissociated. To remove myelin debris and cell clumps, a partial purification step was performed by centrifugation through a $15 \%$ BSA cushion. DRG neurons were then plated at a density of 1500 cells per $\mathrm{cm}^{2}$ on slides (LabTek) precoated with poly-D-lysine (100 $\mu \mathrm{g} / \mathrm{ml}$, Sigma) and laminin $(10 \mu \mathrm{g} / \mathrm{ml}$, Invitrogen) in Neurobasal-A media (Invitrogen) supplemented with B27 (Invitrogen), as previously described (Parikh et al., 2011). Cultures were treated with MS-275 at the indicated concentrations, with or without BMP7 $(1 \mu \mathrm{g} / \mathrm{ml})$ or BMP4 $(50 \mathrm{ng} / \mathrm{ml})$, for 24 to $48 \mathrm{~h}$. Cells were then fixed with $4 \%$ PFA, and axon lengths were revealed by immunostaining of $\beta$-tubulin (Tuj1, Covance, 1:1000). For each experiment, $>100$ DRG neurons were randomly selected, and the longest neurite from each neuron was traced, the length of which was measured using ImageJ and averaged. Three independent sets of experiments were performed.

Immunohistochemistry. L5 DRGs were dissected, fixed in 4\% PFA for $1 \mathrm{~h}$, cryoprotected in $30 \%$ sucrose, embedded in OCT, and sectioned ( 10 $\mu \mathrm{m})$. Frozen sections were permeabilized with $0.1 \%$ Triton $\mathrm{X}-100$ (Sigma), treated with blocking buffer $(0.1 \mathrm{~m}$ phosphate buffer, $5 \%$ normal goat serum, Invitrogen), and incubated with rabbit AcH4 (Millipore, 1:2000), mouse Tuj1 (Covance, 1:1000), mouse NeuN (Millipore, 1:200), or rabbit pSmad1 (Cell Signaling Technology, 1:250) overnight at $4^{\circ} \mathrm{C}$. Frozen spinal cord sections were incubated with either mouse GFAP (Millipore, 1:500) or CSPG (Sigma, 1:100). After incubation with secondary antibodies, the sections were counterstained with DAPI (1:1000; Invitrogen) and mounted in Fluoromount (EMS). Images were captured with an Axio Imager.A2 (Zeiss) microscope equipped with an AxioCam MRc.

Chromatin immunoprecipitation (ChIP). Assays were performed using the ChIP-IT enzymatic kit according to the manufacturer's instructions (Active Motif). Briefly, freshly dissected DRG neurons or Neuro-2A cells were incubated for $12 \mathrm{~min}$ or $10 \mathrm{~min}$, respectively, at room temperature with gentle shaking in $1 \%$ formaldehyde solution. The cross-linking reaction was stopped by addition of glycine to a final concentration of 0.25 M. Cross-linked chromatin was sheared by enzymatic digestion following the manufacturer's recommendations to yield an average fragment size of 150-200 bp. Samples were incubated with 3-5 $\mu \mathrm{g}$ of antibodies against AcH4 (Millipore), HDAC1 (Abcam), p300 (Millipore), pSmad1 (Cell Signaling Technology), or water, together with magnetic beads on a rotator at $4^{\circ} \mathrm{C}$ overnight. This was followed by crosslinking reversal, proteinase $\mathrm{K}$ digestion, and the recovered DNA was purified using QIAGEN QIAquick PCR purification kit (QIAGEN) and subjected to quantitative PCR. Chromatin that was not used for immunoprecipitation was used as control (input) and diluted 1:10 for normalization. Specific bindings of pSmad1 to promoters were calculated by subtracting the noise determined by water (with magnetic beads but no antibodies) and then normalized to diluted input. Values on the graphs are shown as relative enrichment, comparing treatment groups to controls, with control groups arbitrarily assigned as 1. Multiple primer pairs were designed to cover Smad binding elements (SBEs) in promoters or coding regions. Primer sequences are available upon request.

$q R T-P C R$. RNAs from freshly collected DRGs and cultured DRG neurons or Neuro-2A cells were isolated using RNeasy Micro kit (QIAGEN) and Trizol reagent, respectively. A total of $1 \mu \mathrm{g}$ of total RNA was used for reverse transcription reaction (SuperScript III RT-PCR kit, Invitrogen). qRT-PCR was performed using SYBR Green PCR master mix (QuantaBiosciences) in Stratagene PCR System. The melting curve of each sample was measured to 


\section{A Conditioning lesion paradigm}

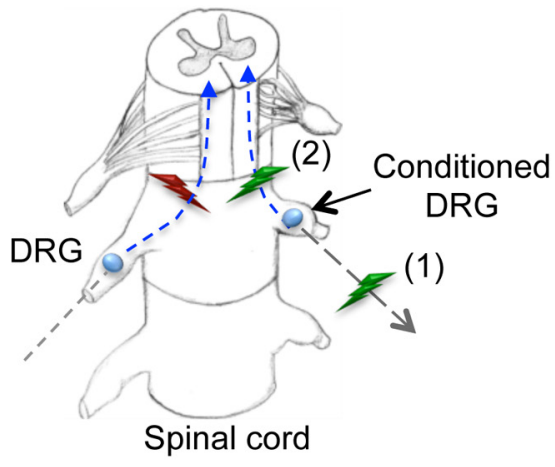

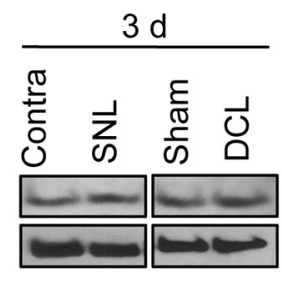

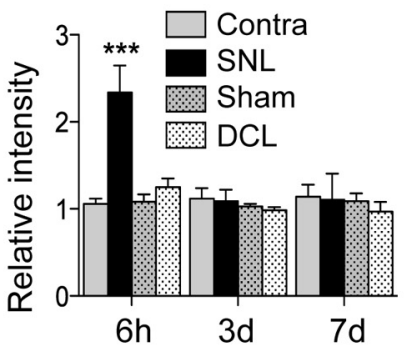

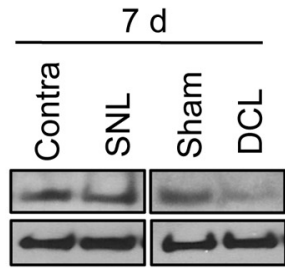
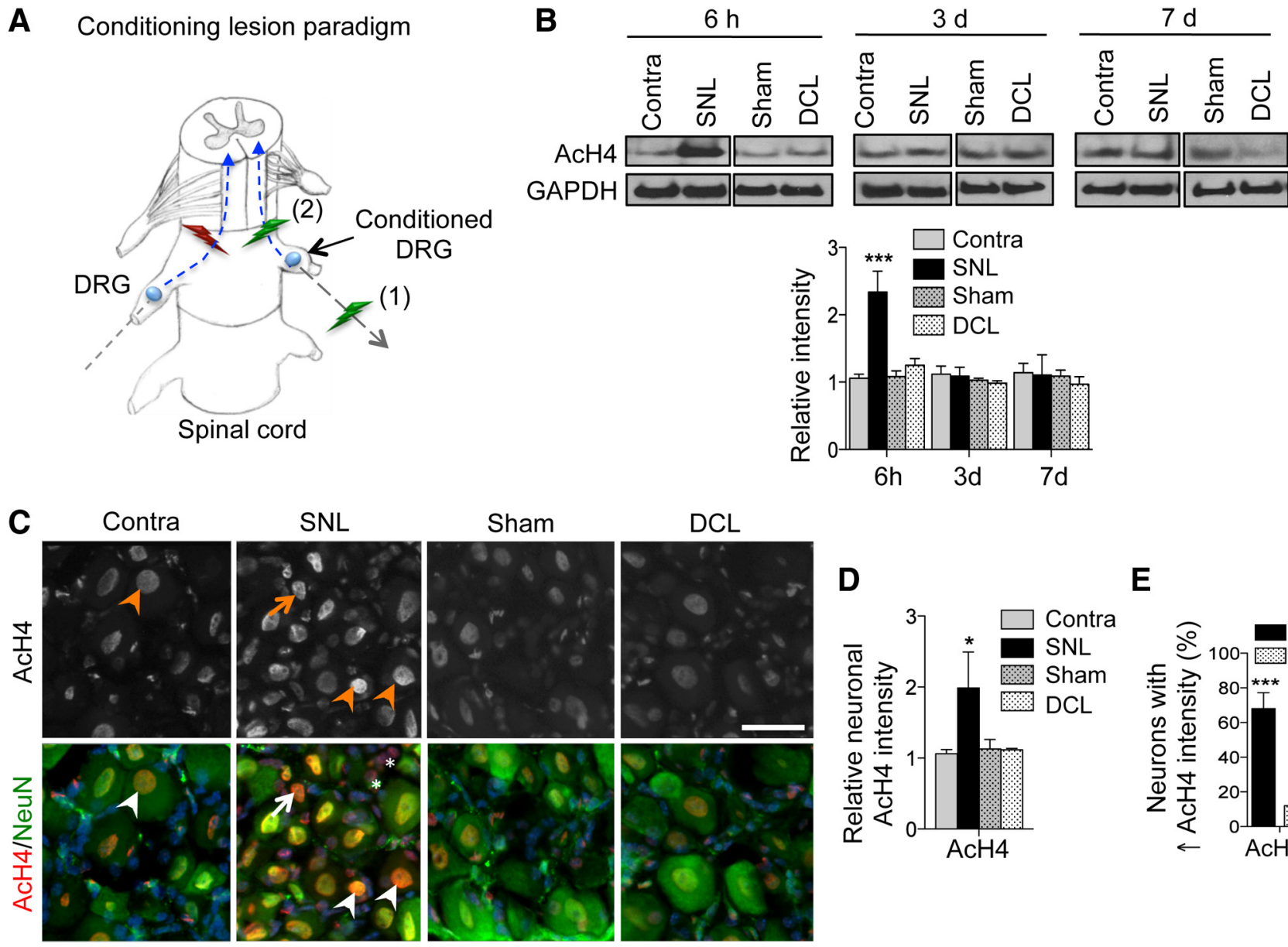
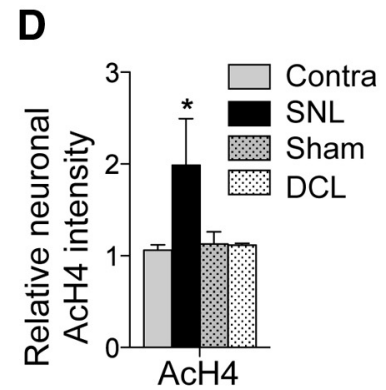

E

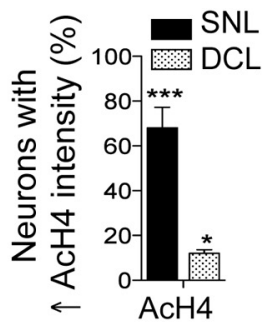

Figure 1. Global levels of AcH4 are increased in DRG neurons after peripheral axotomy. A, Schematic diagram of the conditioning lesion paradigm. DRG neurons (depicted as blue circles) have pseudounipolar axons with two branches: a peripheral branch innervating sensory targets (gray) and a central branch (blue) projecting into the spinal cord. The two branches react differently to axotomy: the peripheral branch can regenerate, but the central branch is refractory to regeneration. However, the central branch can be triggered into a growth state (2) if the peripheral branch is axotomized first (1), the so-called conditioning lesion. $\boldsymbol{B}$, Western blot images and quantification of AcH4 levels in L4, L5, and L6 DRGs of mice $6 \mathrm{~h}, 3 \mathrm{~d}$, and $7 \mathrm{~d}$ after sciatic nerve lesion (SNL, peripheral axotomy) or dorsal column lesion (DCL, central axotomy); contralateral DRGs (Contra) and DRGs from mice subjected to laminectomy (Sham) were used as controls, respectively ( $n=6$ independent experiments). $\boldsymbol{C}-\boldsymbol{E}$, Representative immunohistochemistry images $(\boldsymbol{C})$ and quantification $(\boldsymbol{D})$ of relative immunoreactivity of $A c H 4$ in $\mathrm{L} 5 \mathrm{DRG}$ neurons (NeuN $\left.{ }^{+}\right) 6 \mathrm{~h}$ after a peripheral or a central lesion. A significantly increased percentage of sensory neurons in L5 DRGs exhibited increased nuclear AcH4 levels after a peripheral lesion (E). Scale bar, $50 \mu \mathrm{m}$. Arrows and arrowheads point to examples of increased nuclear AcH4 immunoreactivity in small- and large-diameter DRG neurons, respectively. Asterisks indicate glial cells in DRGs that did not show detectable changes in AcH4. Data represent mean \pm SEM. ${ }^{*} p<0.05 .{ }^{* * *} p<0.001$.

ensure the specificity of the products. Data were normalized to the housekeeping gene RPL13a and analyzed using the $\Delta \Delta \mathrm{C}_{\mathrm{t}}$ method. Primers used in quantitative PCR are available upon request. At least three independent experiments were performed for each condition.

Coimmunoprecipitation. Total cell extracts of adult DRG neurons were prepared in lysis buffer (50 mm Tris pH 7.5, $150 \mathrm{~mm} \mathrm{NaCl}, 1 \%$ CHAPS) supplemented with a mixture of protease inhibitors (Sigma) and phosphatase inhibitors (Sigma). Lysates were quantified using a BCA assay kit (Pierce), and equal amounts of protein were coimmunoprecipitated for $4 \mathrm{~h}$ at $4^{\circ} \mathrm{C}$ with mouse anti-p300 (Millipore) antibody. Immunocomplexes were bound to protein G-Sepharose $4 \mathrm{~B}$ fast flow (Sigma) for $1 \mathrm{~h}$ at $4^{\circ} \mathrm{C}$ and washed with lysis buffer. Western blot analysis was performed using mouse anti-p300 or rabbit anti-Smad1 (Epitomics) primary antibodies and HRP-conjugated secondary antibodies (Jackson ImmunoResearch Laboratories), according to standard procedures. All coimmunoprecipitation experiments were performed a minimum of three times.

Western blot analysis. Lysates from freshly collected DRGs were prepared in $50 \mu \mathrm{l}$ RIPA (Sigma), supplemented with protease inhibitors (Sigma) and phosphatase inhibitor mixture (Sigma), and homogenized using a glass tissue grind pestle (Kimble Chase). Protein levels were quantified using BCA assays (Pierce Thermo Scientific). Proteins were run on NuPAGE gels (Invitrogen) using the XCell SureLock (Invitrogen). The immunoreactive bands were detected by ECL Western Blotting Detection System (GE Healthcare). Equal protein loading was controlled by probing the blots with antibody to GAPDH or histone 3 (H3). Densitometry of the protein bands was analyzed using NIH ImageJ software and normalized to the density of GAPDH or H3. The antibodies used were rabbit AcH4 (Millipore, 1:2000), rabbit H3 (Abcam, 1:1000), and mouse GAPDH (Covance, 1:1000).

Promoter sequence analysis. Regions 2000 bp upstream of the transcription start site of the four RAGs identified as potential Smad1 target genes were analyzed for sequences that have been identified as SBEs (Kusanagi et al., 2000; Morikawa et al., 2011). Only GC-rich regions that were conserved between human, mouse, and rat were considered. Human, mouse, and rat sequences were aligned using Clustal Omega (EMBL-EBI).

Statistical analysis. Prism GraphPad software was used for Student's $t$ test, one-way, and two-way ANOVA followed by Bonferroni's post hoc test for multiple comparisons. Data are presented as mean \pm SEM.

\section{Results}

Global histone acetylation level correlates with axon growth potential

To determine whether axon regeneration is associated with histone acetylation levels, we measured the global abundance of 

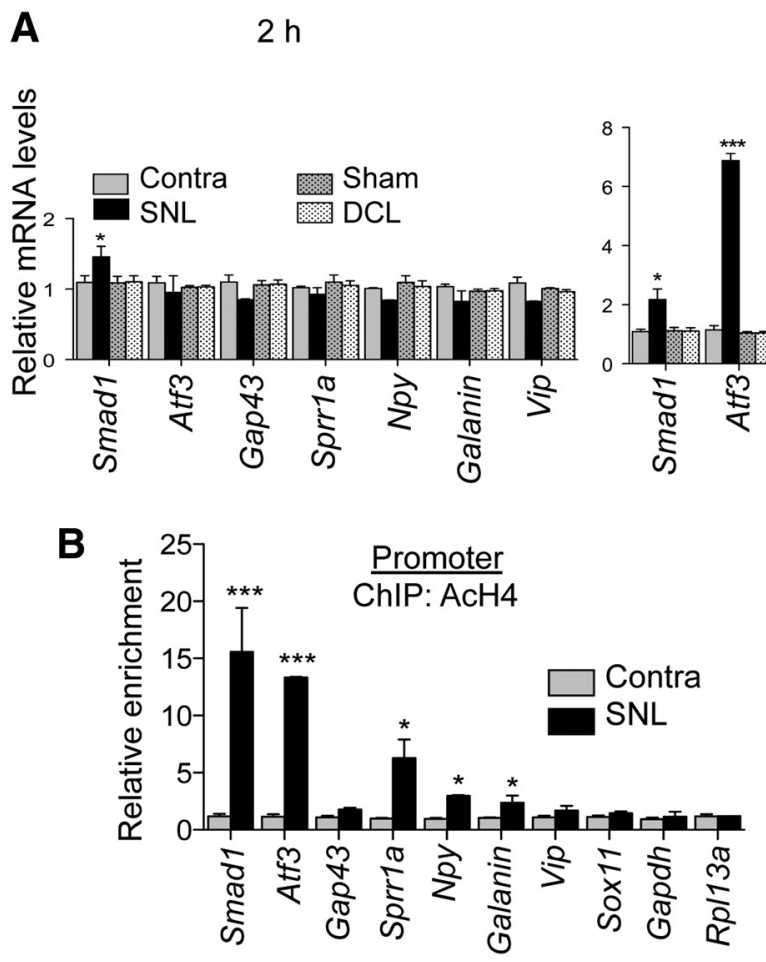

$6 \mathrm{~h}$

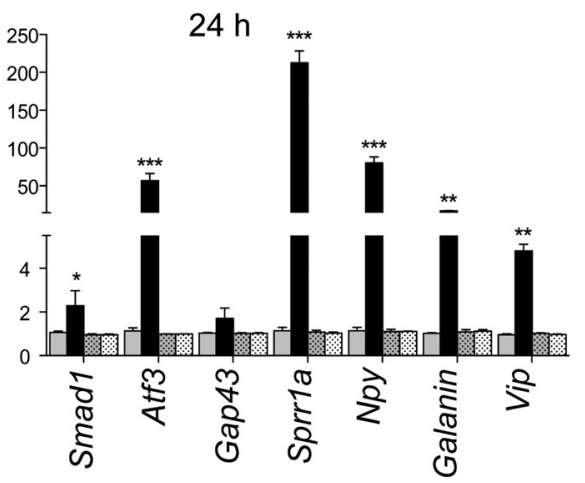

Figure 2. AcH 4 is specifically enriched at promoters of RAGs after peripheral axotomy. A, qRT-PCR of RAGs in mRNA extracts from L4 $-\mathrm{L} 6 \mathrm{DRGs} 2,6$, or $24 \mathrm{~h}$ postlesion ( $n=3$ independent experiments). B, Quantitative PCR results of chromatin immunoprecipitated with ACH4 antibody at the promoters (left) or internal coding region (right) of RAGs and housekeeping genes (Gapdh or Rpl13a) in freshly dissected ipsilateral or contralateral L4-L6 DRGs from mice $6 \mathrm{~h}$ after sciatic nerve lesion (SNL). Relative enrichment of ChIP values is depicted as fold changes over contralateral control DRGs after normalization to input. Data represent mean \pm SEM. ${ }^{*} p<0.05 .{ }^{* *} p<0.01 .{ }^{* * *} p<0.001$.

histone acetylation in adult DRG neurons with or without peripheral axotomy. Western blot analysis showed that the levels of acetylated histone 4 (AcH4) were low in noninjured DRG neurons but markedly increased in conditioned DRG neurons (Fig. 1B). The AcH4 enrichment was detectable at $6 \mathrm{~h}$ after lesion but had returned to baseline after 3 or $7 \mathrm{~d}$ (Fig. $1 B$ ). The increase in $\mathrm{AcH} 4$ was specific to peripheral axotomy because a central lesion or laminectomy alone had no significant effect on AcH4 levels (Fig. 1B). Immunohistochemistry demonstrated that the AcH4 enrichment occurred primarily in neurons $\left(\mathrm{NeuN}^{+}\right)$rather than glial cells $\left(\mathrm{NeuN}^{-}\right)$in the conditioned DRGs, and it appeared in both large- or small-diameter DRG neurons (Fig. 1C,D). An estimated $68.1 \pm 9.1 \%$ neurons in L5 DRGs exhibited an increase in $\mathrm{AcH} 4$ immunoreactivity after a sciatic nerve transection relative to background levels in contralateral DRG neurons, whereas only $12.0 \pm 1.6 \%$ neurons showed an increase after a central lesion (Fig. 1E). Notably, not all neurons in the lumbar L5 DRGs undergo peripheral axotomy after a sciatic nerve transection as some DRG neurons project their peripheral axonal branches to the dorsal ramus of spinal nerves to innervate local tissues, and thus were spared of axonal injury. Together, these data suggest a correlation between AcH4 levels and axon growth potential in DRG neurons.

\section{AcH4 is specifically enriched in RAGs promoters after peripheral axotomy}

A conditioning lesion triggers transcriptional regulation of a large repertoire of RAGs (Skene, 1989; Smith and Pate Skene, 1997). We therefore investigated whether peripheral axotomy is associated with not only a global increase in $\mathrm{AcH} 4$, but also a selective enrichment of AcH4 at the promoters of RAGs. Because AcH4 enrichment occurred as early as $6 \mathrm{~h}$ after sciatic nerve tran- section, we first set out to identify RAGs that were induced early after peripheral axotomy. We focused on 2, 6, and $24 \mathrm{~h}$ after central or peripheral axotomy and surveyed the transcriptional dynamics of a number of RAGs previously shown to be specifically induced in sensory neurons after a peripheral lesion (Skene, 1989; Bosse et al., 2001; Costigan et al., 2002; Xiao et al., 2002; Ylera et al., 2009; Zou et al., 2009). We found a few early waves of RAG induction after peripheral but not central axotomy: Smad1 was induced at $2 \mathrm{~h}$, followed by activating transcription factor 3 (Atf3), small proline-rich protein 1a (Sprrla) and Galanin at $6 \mathrm{~h}$, and neuropeptide $\mathrm{Y}(\mathrm{N} p \mathrm{y})$ and vasoactive intestinal peptide (Vip) at $24 \mathrm{~h}$ (Fig. 2A). Notably, Gap43, a widely used regeneration marker, was not significantly upregulated by $24 \mathrm{~h}$ (Fig. $2 A$ ).

To detect gene-specific changes of promoter histone acetylation after a peripheral axotomy, we performed ChIP assays using antibodies against $\mathrm{AcH} 4$ in conditioned DRGs compared with nonconditioned counterparts. We found that, at $6 \mathrm{~h}$ after peripheral axotomy, AcH4 was enriched at the promoters of Smad1, Atf3, Sprrla, Npy, and Galanin, but not of housekeeping genes, Gapdh and Rpl13a (Fig. 2B). Internal coding regions of the RAGs tested did not show changes in AcH4 levels (Fig. 2B). Gap43 (induced later) and several other early RAGs, such as Vip or Sox 11, also exhibited no changes in AcH4 levels (Fig. 2B). Thus, AcH4 is selectively enriched at the promoters of a subset of early RAGs.

\section{Inhibition of HDAC activity induces RAG transcription in DRG neurons}

Next, we wanted to establish whether AcH4 enrichment is correlated with RAG induction. Histone acetylation levels are regulated by the activity of HATs versus HDACs. We therefore tested whether treatment with TSA, a Class I/II HDACi, or MS-275, an HDAC1-specific inhibitor (Saito et al., 1999), would be sufficient 
to increase AcH4 levels and induce early RAG transcription. First, Western blot and immunostaining demonstrated that systemic TSA or MS-275 treatment significantly increased AcH4 levels in DRG neurons, similar to what occurs after a peripheral lesion (Fig. 3A-C). Next, ChIP assays showed that MS-275 treatment resulted in selective AcH4 enrichment at the promoters of Sprrla, Npy, Galanin, and Vip, but not of housekeeping genes Gapdh or Rpl13a, or internal coding regions of these RAGs (Fig. 3D). Concomitantly, mRNA levels of these early RAGs were markedly increased in DRGs with MS-275 treatment (Fig. 3E). Notably, MS-275 treatment did not increase the AcH4 levels at the promoters of $S m a d 1$ or Atf 3 , or their transcription (Fig. 3D,E), despite both being early RAGs with conditioningtriggered $\mathrm{AcH} 4$ enrichment at their promoters; thus, additional regulatory mechanisms are likely involved for the induction of Smad1 and Atf3. TSA treatment resulted in similar findings (data not shown).

So far, we have focused on early-wave RAGs and established an association between AcH4 enrichment by HDACi and induction of a subset of early RAGs. Next, we investigated whether HDACi can induce transcriptional changes of a larger repertoire of RAGs, including late-onset RAGs. To this end, we extended the survey to a total of 25 known RAGs and found that 13 (52\%) exhibited transcriptional changes after MS-275 treatment, among which 10 (40\%) showed concordant transcriptional changes when comparing MS-275 treatment and peripheral axotomy, and 3 (12\%) showed discordant changes (Fig. 3F, G; Table 1). The rest of the 12 RAGs (48\%) showed no statistically significant transcriptional changes after MS-275 treatment (Fig. 3G). Our data therefore suggest that $\mathrm{H} 4$ acetylation serves as a biomarker of transcriptional activation of multiple RAGs induced by HDACi; but whether it participates in RAG induction after a peripheral axotomy awaits future investigation. Moreover, HDACi treatment may result in acetylation of histone $\mathrm{H} 3$ as well as other nonhistone proteins, which may also be involved in the transcriptional regulation of RAGs. It is also notable that, even though the direction of the transcriptional changes of 10 of the 25 RAGs tested were the same after peripheral axotomy versus MS-275 treatment, the magnitude of the changes was different, consistent with the notion that histone acetylation pertains to only one of the many mechanisms by which peripheral axotomy affects gene transcription in adult sensory neurons (Table 1).

\section{HDAC inhibitor administration enhances axon growth} potential of adult sensory neurons

To investigate whether pharmacological modulation of acetylation levels by HDACi would impact the axon growth potential of
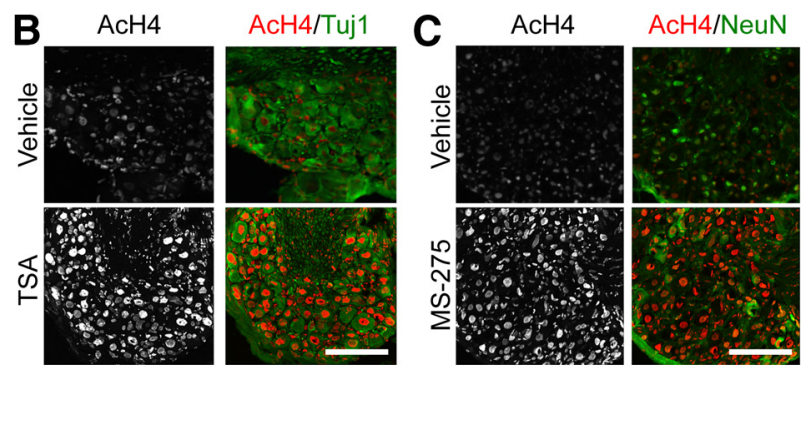

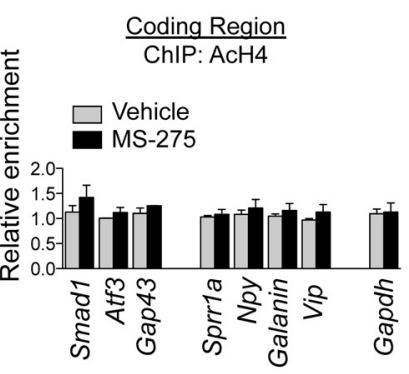

$\mathbf{F}$

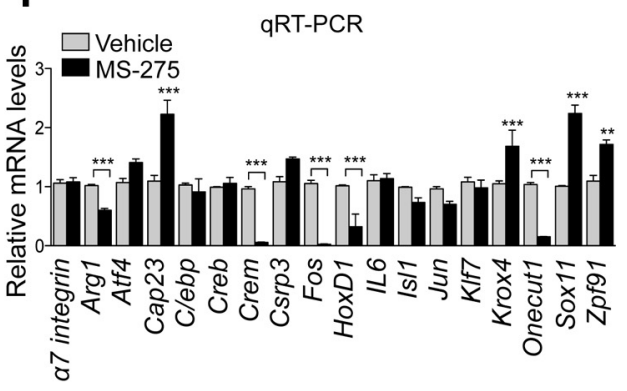

G

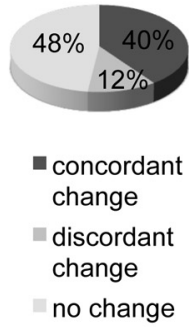

gure 3. HDAC inhibitor induces RAG transcription in sensory neurons. $\boldsymbol{A}$, Western blot images and quantification of $\mathrm{AcH} 4$

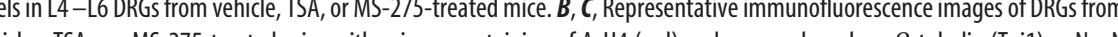
(green). Scale bar, $100 \mu \mathrm{m}$. D, Quantitative PCR results of chromatin immunoprecipitated with AcH4 antibody at the promoter (left) or internal coding region (right) of RAGs and housekeeping genes (Gapdh and Rp/13a) in freshly dissected DRGs $6 \mathrm{~h}$ after the ast of the 4 daily injections of vehicle or MS-275. $E$, qRT-PCR results of RAGs in mRNA extracts from DRGs of the same animals as in (1) of $40 \%$ exhibited same direction of transcriptional changes after MS- 275 treatment compared with a conditioning lesion (concordant change), whereas $12 \%$ exhibited opposite direction of transcriptional changes (discordant change) (G). Data represent mean \pm SEM. ${ }^{*} p<0.05 .{ }^{* *} p<0.01 .{ }^{* *} p<0.001$.

DRG neurons, we used DRG cultures for neurite outgrowth assays. We first added MS-275 directly to freshly dissociated DRG neurons in a dose-response study but found no significant differences in the mean axonal length, or the percentage of axonbearing neurons compared with controls at either $24 \mathrm{~h}$ (reflecting axon initiation capability) with $2 \mu \mathrm{M}$ MS-275, or $48 \mathrm{~h}$ (reflecting axon growth potential) with $0.5,1,2$, or $5 \mu \mathrm{M}$ MS-275 (data not shown). We reasoned that direct MS-275 treatment in DRG cultures may be inadequate to bring out a further gain in axon growth potential because dissociated DRG neurons are capable of initiating axonal outgrowth and extending long axons after undergoing a "priming" period within the first $24 \mathrm{~h}$, during which time RAGs are induced (Smith and Pate Skene, 1997; Zou et al., 2009). We therefore tested the effect of in vivo treatment of HDACi on axon growth potential of DRG neurons. Neurite outgrowth assays showed that DRG neurons from both TSA- or MS-275-treated mice grew longer axons than those from vehicletreated mice, with the mean maximal axonal lengths at $48 \mathrm{~h}$ being 
Table 1. Comparison of the transcriptional changes of RAGs in DRGs with systemic MS-275 treatment versus peripheral axotomy ${ }^{a}$

\begin{tabular}{|c|c|c|c|c|}
\hline & Genes & MS-275 (fold $\Delta \pm$ SEM) ${ }^{b}$ & Peripheral axotomy (fold $\Delta \pm$ SEM) ${ }^{c}$ & References \\
\hline \multirow[t]{12}{*}{ No significant change with MS- 275 treatment } & Smad1 & $1.3 \pm 0.2$ & $2.28 \pm 0.97$ & Current study \\
\hline & Atf3 & $1.0 \pm 0.3$ & $56.9 \pm 3.7$ & Current study \\
\hline & Gap43 & $1.7 \pm 0.9$ & $1.7 \pm 0.7$ & Current study \\
\hline & Integrin & $1.1 \pm 0.1$ & $2.4 \pm 0.3$ & Current study \\
\hline & Atf4 & $1.4 \pm 0.8$ & $1.34 \pm 0.29$ & Current study \\
\hline & Clebp & $0.9 \pm 0.3$ & $2.05 \pm 0.14$ & Current study \\
\hline & Creb & $1.1 \pm 0.1$ & Not determined & \\
\hline & Csrp3 & $1.5 \pm 0.4$ & Not determined & \\
\hline & IL6 & $1.1 \pm 0.1$ & $4.2(18 \mathrm{~h})$ & Cao et al., 2006 \\
\hline & $|s| 1$ & $0.7 \pm 0.2$ & $0.67 \pm 0.49$ & Current study \\
\hline & Jun & $0.7 \pm 0.4$ & $1.81 \pm 0.82$ & Current study \\
\hline & Klf7 & $0.98 \pm 0.2$ & $1.83 \pm 0.26$ & Current study \\
\hline \multirow[t]{3}{*}{ Discordant change } & $\operatorname{Arg} 1$ & $0.6 \pm 0.1$ & $15.3 \pm 1.5(2 \mathrm{w})$ & Ylera et al., 2009 \\
\hline & Crem & $0.05 \pm 0.1$ & $1.86 \pm 0.74$ & Current study \\
\hline & Fos & $0.02 \pm 0.01$ & $2.31 \pm 0.47$ & Current study \\
\hline \multirow[t]{10}{*}{ Concordant change } & Sprr1a & $10.2 \pm 2.9$ & $212.5 \pm 22.3$ & Current study \\
\hline & Npy & $11.2 \pm 6.0$ & $80.4 \pm 10.8$ & Current study \\
\hline & Galanin & $2.5 \pm 1.0$ & $16.9 \pm 0.5$ & Current study \\
\hline & Vip & $8.7 \pm 0.8$ & $4.8 \pm 0.4$ & Current study \\
\hline & Cap23 & $2.2 \pm 0.3$ & $2.0 \pm 0.3$ & Current study \\
\hline & Krox4 & $1.7 \pm 0.4$ & $2.7 \pm 0.8$ & Current study \\
\hline & Sox11 & $2.2 \pm 0.2$ & $6.7 \pm 0.46$ & Current study \\
\hline & Zpf91 & $1.7 \pm 0.1$ & $1.6 \pm 0.3$ & Current study \\
\hline & HoxD1 & $0.3 \pm 0.3$ & $0.4 \pm 0.17$ & Zou et al., 2009 \\
\hline & Onecut1 & $0.15 \pm 0.005$ & $0.47 \pm 0.21$ & Current study \\
\hline
\end{tabular}

${ }^{a}$ List of relative fold changes of the mRNA levels by qRT-PCR of 25 RAGs in DRGs with MS-275 versus vehicle treatment, or with peripheral axotomy versus no lesion after the indicated time periods. Results are shown as mean \pm SEM.

${ }^{b}$ Six hours after the last of the four daily subcutaneous injections of MS- 275.

'Twenty-four hours after peripheral axotomy, unless otherwise specified in parentheses.

$618.1 \pm 19.3 \mu \mathrm{m}$ for vehicle, $819.1 \pm 66.5 \mu \mathrm{m}$ for TSA (a $32.5 \%$ increase, $p<0.01$ ), and $753.8 \pm 69.0 \mu \mathrm{m}$ for MS-275 (a $22.0 \%$ increase, $p<0.05$ ) (Fig. $4 A$ ). The percentage of axon-bearing neurons at $48 \mathrm{~h}$ showed no change between vehicle- versus TSA or MS-275-treated DRGs $(70.4 \pm 6.7 \%$ vs $69.7 \pm 3.2 \%$ or $72.34 \pm 4.7 \%, p>0.05)$. Thus, we demonstrated that, through systemic pharmacological treatment, AcH4 levels could be increased, along with an increase in axon growth potential. Notably, axon initiation capability appeared to be less affected by HDACi than a conditioning lesion. This is most evident at the 24 h culture period, when $\sim 75 \%$ of conditioned DRG neurons had initiated axonal extension compared with only $16 \%$ of naive neurons. By comparison, $18.0 \pm 4.0 \%, 22.0 \pm 2.0 \%$, or $16.6 \pm$ $1.4 \%$ of DRG neurons from TSA-, MS-275-, or vehicle- treated mice, respectively, had initiated axon extension by $24 \mathrm{~h}$. For those axon-bearing neurons, the mean maximal axonal length at $24 \mathrm{~h}$ in vitro was increased from $157.6 \pm 73.7 \mu \mathrm{m}$ for naive neurons to $577.9 \pm 128.7 \mu \mathrm{m}$ for conditioned DRG neurons (3.7-fold), whereas the TSA group showed a mean axonal length that was 1.6 -fold greater than that of the vehicle group $(p=0.041)$. The MS-275 group displayed a trend of increase (1.3-fold), which did not reach statistical significance $(p=0.26)$. The different effects on the axon initiation capacity underscore the difference between HDACi treatment and a conditioning lesion. Notably, by $48 \mathrm{~h}$, naive DRGs have had sufficient time to initiate and extend axons after the "priming" period, resulting in a smaller difference in axonal length between conditioned and naive DRGs $32.4 \%$ increase), which is similar to the extent of increase with HDACi treatment (Fig. 4A).

Systemic administration of HDACi caused minimal toxicity to DRG neurons as neuronal survival was comparable between treatment groups (data not shown). Remarkably, DRG neurons collected 2 weeks after the final MS-275 injection exhibited a sustained enhancement in axon growth capacity, whereas AcH4 levels at the RAG promoters and corresponding mRNA levels had largely returned to baseline (except for $N p y$ ) (Fig. $4 B, C$ ). Therefore, short-term treatment with HDACi results in a sustained active axon growth program.

\section{Histone-modifying enzymes collaborate with Smad1 to regulate RAG expression}

Successful gene transcription often involves the collaborative effort of epigenetic modulators and TFs for coordinated recruitment to target genes (Ram et al., 2011). We therefore asked whether such collaboration is operational in regenerating DRG neurons. Previously, we identified Smad1 as a TF critically involved in sensory axon regeneration (Zou et al., 2009). Here, we first assessed the temporal dynamics of the nuclear accumulation of pSmad1 in DRG neurons after a peripheral axotomy. The nuclear pSmad 1 immunoreactivity appeared at $6 \mathrm{~h}$ after conditioning, peaked at $3 \mathrm{~d}$, and settled to a lower plateau but remained above baseline by $7 \mathrm{~d}$ (Fig. $5 \mathrm{~A}$; and data not shown). Our previous studies have shown that DRG neurons from Smad1 conditional knock-out mice (cKO mice, Smad1 ${ }^{\mathrm{fl} /-}$; Wnt1-Cre with Smad1 ablated in neural crest-derived cells, including DRG neurons; Fig. $5 B$ ) grow shorter neurites compared with DRGs from wild-type littermates (Parikh et al., 2011). We therefore asked whether this might be associated with dysregulation of early RAG transcription. Smad1 target genes in conditioned DRG neurons are unknown; so we first compared the abundance of RAGs mRNAs in freshly dissected DRGs from Smad1 cKO mice to littermate controls. Sprrla, Npy, and Galanin mRNA levels were all significantly lower in mutant DRGs, whereas Atf3 or Gap43 expression was unaltered (Fig. 5C). Consistently, putative SBEs were present in the promoters of the potential Smad1 target genes (Fig. 5D). 
We then conducted the following set of studies in a neuronal cell line (Neuro-2A cells) to collect sufficient chromatin material. First, siRNA-mediated Smad1 knockdown led to a downregulation of Sprrla, Npy, Galanin, and Vip, whereas BMP4 stimulation, which activates Smad1, resulted in an upregulation of these potential Smad1 target genes, with the exception of Vip (Fig. 6A,D). Next, we demonstrated that Smad1 knockdown indeed resulted in a significant decrease in pSmad1 occupancy at the promoters of Sprrla, Npy, and Galanin, and, to a lesser extent, Vip (Fig. 6B), whereas BMP4 stimulation led to opposite effects. In contrast, pSmad1 did not appear to specifically bind to the promoters of Atf3 and Gap43, or the two housekeeping genes (Gapdh and $R p l 13 a$ ), or internal coding regions of the RAGs (Fig. 6G), as regardless of the abundance of pSmad1 (either by siRNA knockdown or BMP stimulation), there was no change in pSmad1 binding by ChIP assays (Fig. 6B, $C, E, F$ ). Next, we tested whether a change in pSmad1 promoter occupancy would affect AcH4 levels at the promoter of Smad1 target genes. Notably, depletion of Smad1 correlated with a substantial decrease in AcH4 in Sprr1a, Npy, and Galanin promoters, but not the coding regions, whereas $\mathrm{BMP} 4$ treatment led to the opposite (Fig. 6B,E,G). By comparison, such changes were again absent in nontarget genes, Atf3 and Gap43, although Atf3 mR-

NAs were increased by BMP4, despite the absence of change in pSmad1 binding, thus implicating an indirect effect of BMP4 or involvement of a noncanonical, Smad1-independent pathway for Atf3 regulation (Fig. $6 D$ ). Together, our results suggest a positive correlation between $\mathrm{pSmad} 1$ promoter occupancy and histone acetylation at promoters of Smad1 target genes.

Elevated histone acetylation levels can relax local chromatin, which conceivably may enhance accessibility of TFs to the respective DNA binding sites. We tested this model by using MS-275 to elevate histone acetylation levels in Neuro-2A cells and then conducted ChIP assays to assess pSmad1 occupancy at promoters of Smad1 target genes. We found that MS-275 treatment led to an increase in $\mathrm{pSmad} 1$ binding at promoters but not coding regions of these early RAGs, which correlated with their enhanced transcription (Fig. $6 \mathrm{H}, \mathrm{I}$; and data not shown). In sum, these data suggest a positive reinforcement loop between pSmad1 binding and histone acetylation at the promoters of Smad1-target RAGs. In further support of this collaboration in DRGs, we found that Smad1 was necessary for MS-275-mediated induction of Sprrla and $N p y$, as mutant DRGs from Smad1 cKO mice showed significantly attenuated upregulation of these genes after MS-275 treatment, compared with wild-type DRGs (Fig. 6J).

To gain mechanistic understanding of how $\mathrm{pSmad} 1$ promoter occupancy is correlated with histone acetylation, we conducted additional ChIP assays to test whether recruitment of histonemodifying enzymes to RAG promoters could be facilitated by pSmad1 binding. Because Smad1 has been shown previously to interact with HDAC1 and p300 (one of the HATs) (Pearson et al.,
1999; Kim and Lassar, 2003; Ross et al., 2006; Jun et al., 2010), we focused on the promoter binding of these two histonemodifying-enzymes. We found an inverse correlation between pSmad1 promoter occupancy and HDAC1 binding: when pSmad1 binding was reduced by Smad1 deletion, HDAC1 binding was increased at the promoters of the four Smad1 target genes identified (Fig. 6B,C); in contrast, when pSmad1 binding was increased by BMP4 stimulation, HDAC1 binding was decreased at the RAG promoters (Fig. $6 E, F$ ). On the other hand, pSmad1 binding appeared to be positively correlated with p300 binding at the Sprrla promoter, as when Smad1 was knocked down by siRNA or activated by BMP4, p300 binding was reduced or increased, respectively (Fig. 6C,F). The effect of pSmad1 on p300 promoter binding was more variable in the other three RAGs (Npy, Galanin, and Vip), suggesting a greater reliance on HDAC1 for their expression. The changes in HDAC1 or $\mathrm{p} 300$ promoter binding were absent in Atf3, Gap43, housekeeping genes, or coding regions of the RAGs tested (Fig. 6C,F; and data not shown). In further support of this collaboration model, coimmunoprecipitation studies demonstrated interaction of pSmad1 with p300 in the conditioned adult DRGs (Fig. 6K). Notably, for different Smad1 target genes, the degree of reliance on AcH4 enrichment or Smad1 activation for their transcriptional regulation varies, indicating the complexity of regulatory mechanisms. Together, these data obtained in Neuro-2A cells suggest that BMP/Smad1 signaling and histone-modifying enzymes work together in the transcriptional regulation of a subset of Smad1 target genes. Future ChIP studies using neuronal-specific chromatin from DRGs 


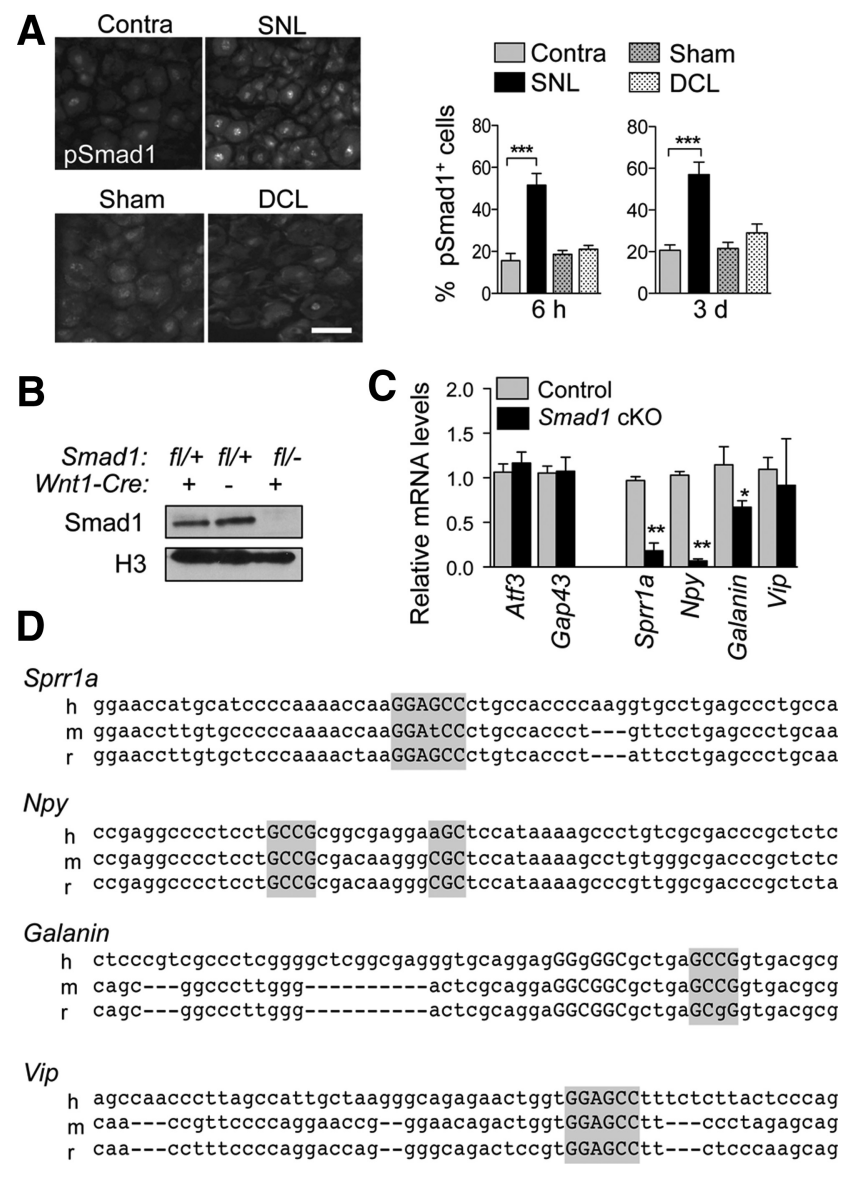

Figure 5. Smad1 induces target genes in conditioned DRG neurons. $\boldsymbol{A}$, Representative immunohistochemistry images and quantification of pSmad $1^{+}$neurons in L5 DRG $6 \mathrm{~h}$ and $3 \mathrm{~d}$ after either sciatic nerve (SNL) or dorsal column lesion (DCL), with control DRGs from contralateral (Contra) or mice with laminectomy only (Sham) ( $n=3$ mice each). Scale bar, $50 \mu \mathrm{m}$. $\boldsymbol{B}$, Western blot using DRG lysates from Smad 1 CKO mice or littermate controls probed for Smad 1 or H3 (as loading control). C, qRT-PCR results of RAGs from mRNA extracted from freshly dissected DRGs from Smad1 CKO or littermate control mice. D, Human, mouse, and rat RAGs promoter sequences are aligned and conserved GC-rich SBEs are highlighted in gray. Data are mean \pm SEM. ${ }^{*} p<0.05 .{ }^{* *} p<0.01 .{ }^{* *} p<0.001$.

would help unravel the regulatory mechanisms of RAG induction in conditioned DRG neurons.

\section{In vivo $\mathrm{HDAC}$ inhibitor treatment enhances sensory axon regeneration after $\mathrm{SCI}$}

Because AcH4 enrichment in DRG neurons appeared specifically after a peripheral axotomy, we postulated that perhaps lack of restoration of AcH4 after a central branch lesion is associated with failure of axon regeneration after SCI. We therefore tested whether administration of TSA or MS-275 would enhance axon regeneration after SCI. Notably, MS-275 has been used in clinical trials for cancer therapy (Minucci and Pelicci, 2006; Juergens et al., 2009).

We used a sensory SCI model where ascending sensory fibers in the fasciculus gracilis were completely severed at cervical level 5 (Fig. $7 A$ ). In vehicle-treated mice, all ascending sensory fibers in the fasciculus gracilis had retracted from the caudal border of the glial scar at 2 weeks after SCI (Fig. 7B). In contrast, in MS-275treated mice, DexTR-labeled ascending sensory axon fibers were found abundantly present in the center of the glial scar, which was defined by GFAP or CSPG immunostaining, in conjunction with DAPI nuclear counterstaining, which highlights an in- creased cellular density at the lesion center (Fig. 7 B, C). Specifically, vehicle-treated mice had an average axon index of $9.0 \%$, $6.0 \%$, and $3.2 \%$ at $-0.3 \mathrm{~mm},-0.2 \mathrm{~mm}$, and $-0.1 \mathrm{~mm}$ caudal to the lesion center, respectively, whereas MS-275-treated mice had an average axon index of $73.9 \%, 67.2 \%$, and $34.1 \%$, respectively (Fig. 7D). A significantly greater number of injured fibers traversed the lesion epicenter, with some even reaching past the lesion, indicating that MS-275 treatment leads to not just reduced axonal die-back, but also some degree of regeneration. We repeated the MS-275 study in an independent cohort and found the same enhancing effect. To rule out a possibility that the enhanced axon regeneration from MS-275 treatment might be related to changes in glial scar formation, we measured lesion volume as defined by dense $\mathrm{GFAP}^{+}$immunoreactivity and found it comparable in vehicle- versus MS-275-treated mice (Fig. 7E), suggesting that enhanced regenerative capacity of adult DRG neurons is a more likely mechanism. TSA treatment similarly led to a promoting effect on sensory axon regeneration, although the effect was less robust compared with MS-275: quantification showed a significant increase in axon index only at $-0.3 \mathrm{~mm}$ caudal to the lesion center $(75.3 \%)$ compared with vehicle-treated mice (24.1\%). Our findings are in agreement with the previously reported beneficial effect of HDACi on the recovery of motor function in animal models of SCI (Lv et al., 2012). Systemic administration of TSA or MS-275 did not lead to gross allodynia in the current study; however, future investigations are needed to exclude subtle changes in sensory perceptions and to evaluate whether regeneration of small-diameter sensory fibers may also be affected.

\section{Discussion}

A major obstacle for neural repair after CNS injury is an agerelated decline in intrinsic axon growth capacity (Zhou and Snider, 2006). One reason for this decline is that genes important for axonal regeneration are not regulated properly after injury. Understanding the transcriptional mechanisms and finding an approach to induce RAGs could potentially help to advance therapeutic interventions for SCI.

\section{Inhibition of HDACs enables induction of multiple RAGs}

Here, we report a novel link between axon growth potential and H4 acetylation. In mature DRG neurons, both global and RAGspecific AcH4 levels are low, and $\mathrm{H} 4$ remains hypoacetylated in DRG neurons after SCI. Remarkably, sensory neurons in the DRG can recover their regenerative capacity after a conditioning lesion, and this is associated with an increase in both global and gene-specific AcH4 levels. Notably, inhibition of the enzymatic activity of HDACs can lead to induction of multiple RAGs, along with restoration of AcH4 levels (Fig. 8). Our results suggest that histone acetylation is a marker of the chromatin modifications induced by a peripheral axotomy. The exact mechanism of axotomy-induced AcH4 enrichment awaits future investigation, although our data implicate a role for an orchestrated activation of TFs and recruitment of histone-modifying enzymes to RAG promoters.

Importantly, targeted pharmacological inhibition of HDACs enables simultaneous induction of multiple RAGs, thus mimicking a conditioning effect. Indeed, MS-275 treatment leads to transcriptional changes of not only early RAGs, such as Sprrla, Npy, Galanin, and Vip, but also 9 additional RAGs, of a total of 25 RAGs examined. Notably, a short-term, 4 day treatment with MS-275 enhances axon growth state for at least 2 weeks, a finding perhaps related to a cascade of gene induction. It is also notewor- 

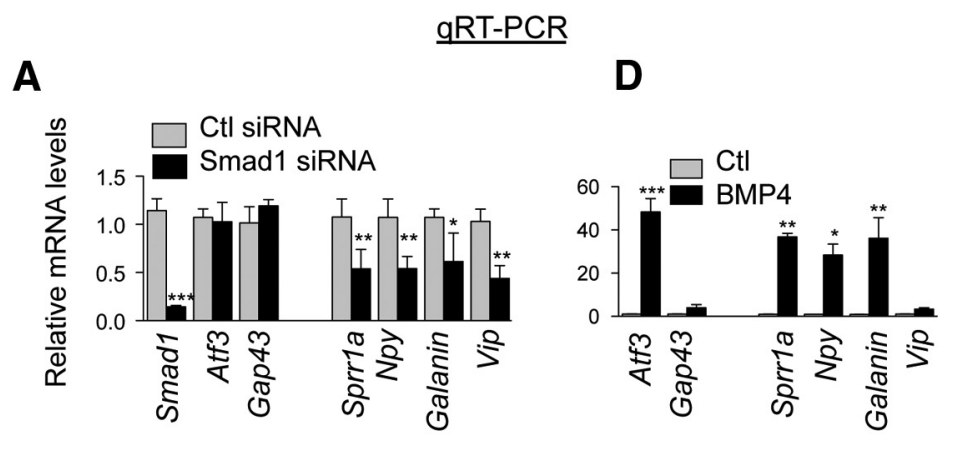

B

Promoter E
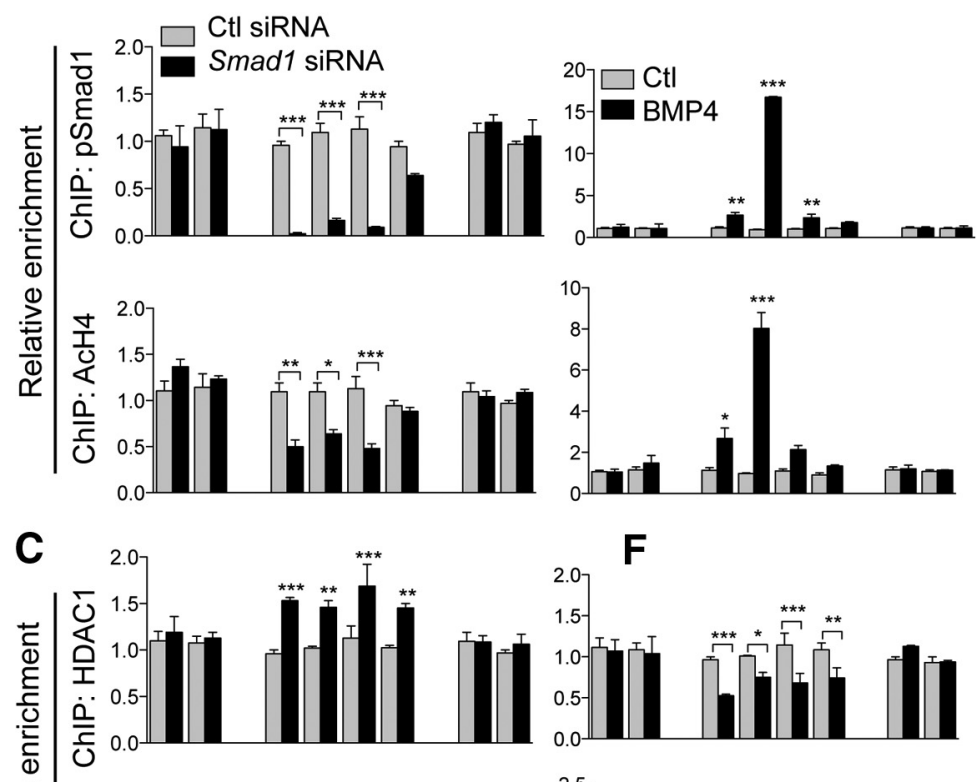

$\mathbf{F}$

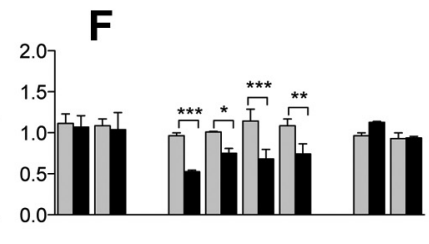

$\frac{\sum_{0}^{0}}{Q}$

G
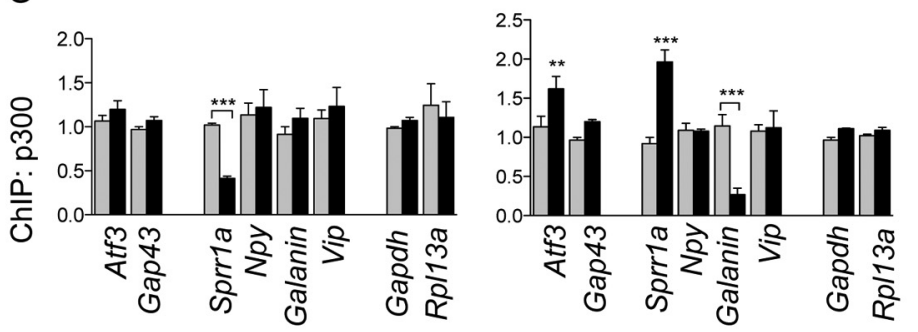

Coding Region
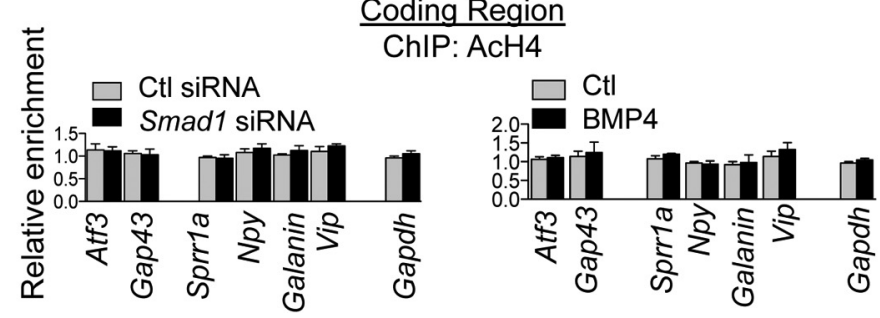

H

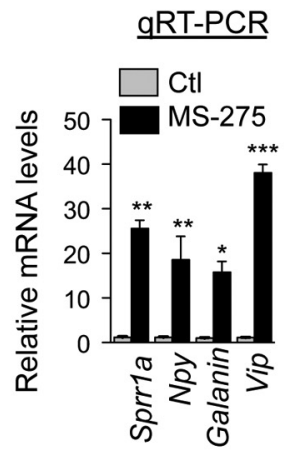

I
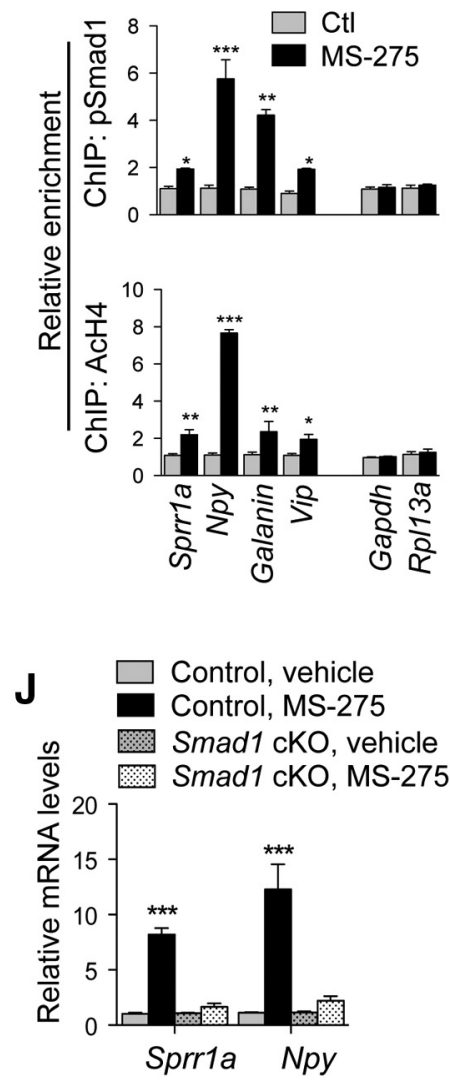

$\mathbf{K}$

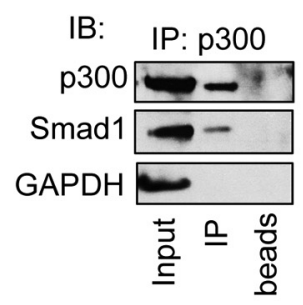

Figure 6. Histone-modifying enzymes collaborate with Smad1 to regulate RAG expression. $\boldsymbol{A}-\mathbf{G}$, pSmad1 binding facilitates histone acetylation at the promoters of Smad1 target genes. qRT-PCR results of RAGs in mRNA extracts from Neuro-2A cells transfected with Smad1 siRNA for $48 \mathrm{~h}(\boldsymbol{A})$ or treated with BMP4 for $8 \mathrm{~h}$ (D); the controls were nontargeting siRNA or vehicle, respectively. $B, C, E, F$, Quantitative PCR results of pSmad1, ACH4-, HDAC1-, or p300-immunoprecipitated chromatin at promoters of the same RAGs and housekeeping genes. For the internal coding region, ChIP results using pSmad1, ACH4, HDAC1, or p300 antibodies all showed no change for the genes tested with Smad1 siRNA or BMP4 treatment, but for simplicity, only the AcH4 ChIP results are shown $(\boldsymbol{G}) . \boldsymbol{H}, \boldsymbol{I}, \mathrm{H} 4$ acetylation facilitates $\mathrm{pS}$ Smad1 promoter occupancy in Smad1 target genes. qRT-PCR results of RAGs from mRNA extracts of Neuro-2A cells treated with MS-275 or vehicle for $48 \mathrm{~h}(\boldsymbol{H})$. Quantitative PCR results of chromatin immunoprecipitated with AcH4 or pSmad 1 antibodies at the promoters of the RAGs and housekeeping genes in Neuro-2A cells $(\boldsymbol{I})$. Relative enrichment of ChIP values is depicted as fold changes over controls after normalization to input. Data represent mean \pm SEM. ${ }^{*} p<$ $0.05 .{ }^{* *} p<0.01 .{ }^{* * *} p<0.001$. J, qRT-PCR results of RAGs from mRNA extracts from freshly cultured dissociated DRG neurons (2 h) from wild-type or Smad 1 cK0 mice treated with vehicle or MS-275. RAG induction by MS-275 was significantly attenuated for Sprr1a and Npy in mutant DRGs compared with wild-type DRGs. $K$, Coimmunoprecipitation with antibody against p300 in lysates of dissociated DRG neurons cultured for $3 \mathrm{~d}$ and immunoblotted for p300, Smad1, or GAPDH. 

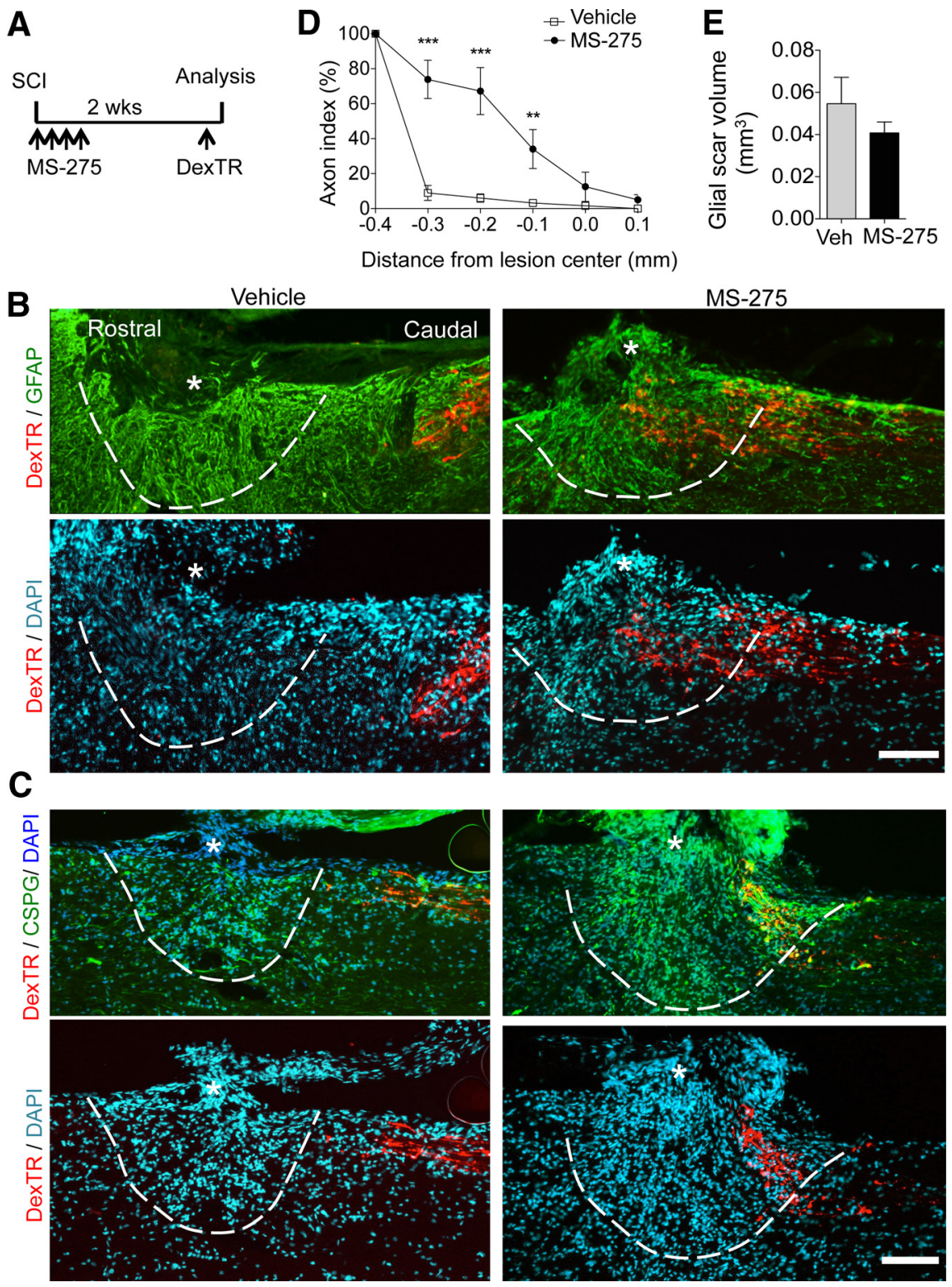

Figure 7. Sensory axon regeneration after $S C l$ is enhanced with $\mathrm{HDACi}$ treatment. $\boldsymbol{A}$, Experimental scheme. After $S \mathrm{Cl}$, animals were injected with either vehicle or HDACi daily for 4 consecutive days. Two weeks after $S C l$, regenerating axons were labeled using DexTR tracer and analyzed $3 \mathrm{~d}$ later. $\boldsymbol{B}, \boldsymbol{C}$, Representative images of sagittal sections of lesion centers of vehicle- or MS-275-treated mice. Ascending sensory axons were labeled with DexTR (red), and lesion borders (marked with dashed lines) were defined by a combination of dense GFAP or CSPG immunoreactivity (green) and DAPI nuclear counterstaining (blue) that demonstrates a gradient of increased cellular density from the lesion center (marked with asterisk). $\boldsymbol{D}$, Axon index of DexTR ${ }^{+}$axons showed that significantly more axons were found at $-0.3,-0.2$, and $-0.1 \mathrm{~mm}$ caudal to the lesion center in MS275-treated mice than controls. $E$, Lesion volume at the spinal cord injury site defined by dense GFAP immunoreactivity ( $n=7$ pairs of mice). Scale bars: $B, C, 100 \mu \mathrm{m}$. Data represent mean \pm SEM. ${ }^{*} p<0.05 .{ }^{* *} p<0.01 .{ }^{* * *} p<0.001$.

thy that a conditioning lesion and MS-275 treatment are not equivalent for a number of reasons: first, a conditioning lesion induces a transcriptional cascade involving a large number of TFs, many of which are not activated by MS-275 treatment (e.g., Smad1 and ATF3). Hence, MS-275 treatment alone is insufficient to initiate a full collaboration between TFs and histonemodifying enzymes. Second, H4 acetylation is only one of the epigenetic mechanisms by which peripheral axotomy regulates RAGs. Indeed, after a central axotomy, we observed an increase of AcH4 levels in $12 \%$ of DRG neurons, yet no regeneration occurs after the central axotomy. One explanation is that, even though global AcH4 levels are increased in certain DRG neurons after a central axotomy, gene-specific AcH4 enrichment may not have occurred. Another explanation is that AcH4 enrichment alone is not sufficient to induce crucial RAGs. Indeed, of the 25 RAGs that are induced by a peripheral axotomy, close to half exhibited no transcriptional changes after systemic MS-275 treatment, and three even showed changes in opposite directions; and for the remaining 10 RAGs, even though they exhibited concordant transcriptional changes, the magnitude of the changes were different (Table 1). Third, a conditioning lesion has minimal direct effects on glial cells, whereas systemic MS-275 treatment may influence gliosis, myelin breakdown, or inflammatory responses at the SCI site, as well as activate glial cells in the DRGs, which may be the source of trophic support for DRG neurons. Fourth, peripheral axotomy is more potent than MS-275 in enhancing axonal regrowth potential as measured by neurite outgrowth assays, in particular, axon initiation capability. A notable caveat of the neurite outgrowth assay (performed on laminin-coated chamber slide devoid of inhibitory substances), however, is that it can only partially inform us on the regenerative outcome in SCI models. For example, TSA treatment appears more potent than MS-275 in neurite outgrowth assays but less so in SCI studies. Future investigations will elucidate potential additive or synergistic effects between histone acetylation and peripheral axotomy.

\section{A regeneration-associated transcriptional module regulates expression of RAGs in conditioned DRG neurons}

Our previous studies have shown that peripheral axotomy leads to induction and activation of Smad1 in axotomized DRG neurons, which is critical for activating the axon growth program. Our current study has identified a set of Smad1 target genes in conditioned DRG neurons and demonstrated that pSmad1 works together with histone-modifying enzymes to facilitate transcription of a subset of RAGs.

Recent studies using ChIP-string and bioinformatics analysis imply that transcriptional modules often consist of a combination of TFs and chromatin remodelers that colocalize at genes of coherent functions and with similar transcriptional timing and levels (Ram et al., 2011; Ernst et al., 2012). A peripheral lesion initiates a complex pattern of transcriptional changes (van Kesteren et al., 2011; Tedeschi, 2012), mediated perhaps by both chromatin remodelers and TFs as part of multinodal transcriptional networks. Thus, in the context of axon regeneration, a specific transcriptional module may regulate stress genes, whereas another may be responsible for RAG induction, etc. To 

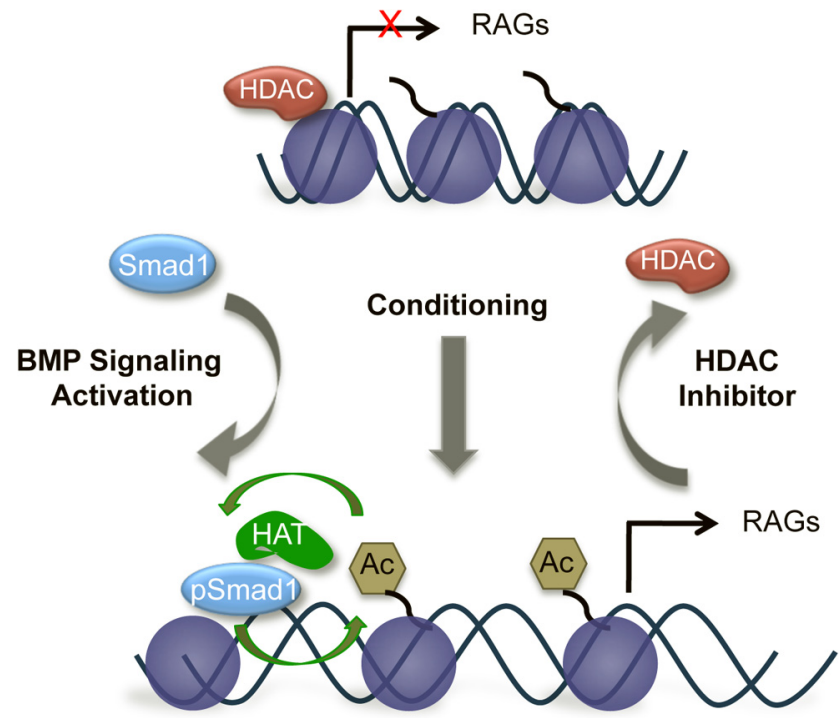

Figure 8. Working model. A conditioning lesion initiates epigenetic reprogramming that includes inducing and activating Smad1, removing HDACs, and recruiting HATs. A collaboration between $\mathrm{pSmad1}$ promoter occupancy and histone acetylation helps to induce Smad1 target RAGs. Importantly, targeted modulation of the activity of this regeneration-associated transcriptional module via BMP signaling activation or pharmacological inhibition of HDACs can mimic the conditioning effect.

our knowledge, the current study identifies, for the first time, a regeneration-associated transcriptional module (consisting of at least pSmad 1 and histone-modifying enzymes) that is associated with the induction of a subset of Smad1 target genes. Future genome-wide ChIP-sequencing studies in neuronal-specific chromatin preparations (Jiang et al., 2008) will help further validate our model and identify additional regeneration-associated transcriptional modules that may regulate other classes of early or late-onset RAGs.

Our data highlight the importance of a combinatorial strategy that can simultaneously turn on epigenetic reprogramming and proregenerative signaling pathways to achieve optimal regeneration. Indeed, enhancing the intrinsic axon growth potential by removing intracellular inhibitors, such as PTEN or Socs3 (Park et al., 2008; Liu et al., 2010; Sun et al., 2011), activating signaling kinases, such as Jnk or Dlk (Nix et al., 2011; Shin et al., 2012), or inducing TFs, such as Stat3 or Smad1 (Huang et al., 2002; Zou et al., 2009), enables only limited regeneration. Our study points to a new approach for axonal repair after CNS injury and suggests that activation of the BMP/Smad1 pathway in conjunction with epigenetic modulation may potentially lead to even greater axonal regeneration. This model needs future in vivo validation as our neurite outgrowth assays in dissociated DRG cultures did not show a detectable enhancement in axon growth potential with combined treatment of MS-275 $(0.5 \mu \mathrm{M})$ and BMP4 $(50 \mathrm{ng} / \mathrm{ml})$ or BMP7 $(1 \mu \mathrm{g} / \mathrm{ml})$ (data not shown). However, these in vitro results need to be interpreted with caution because freshly dissociated DRG neurons are less responsive to BMP stimulation due to loss of BMP receptors during enzymatic dissociation, as shown previously (Zou et al., 2009).

\section{In vivo treatment with HDAC inhibitors promotes axon regeneration}

Previously, myelin-associated proteins as well as proteoglycans secreted by reactive astrocytes have been shown to act as extrinsic inhibitors thwarting the regenerative effort (Cafferty et al., 2007;
Lee et al., 2010). The current findings of an association of RAG repression and promoter $\mathrm{H} 4$ hypoacetylation identify yet another formidable barrier for regeneration, and perhaps explain why neutralizing extrinsic inhibitors alone is insufficient for successful axon regeneration. Encouragingly, this epigenetic inhibition appears to be reversible as demonstrated in conditioned DRG neurons. Because a conditioning lesion is not clinically relevant, we investigated an alternative strategy of pharmacological inhibition of the enzymatic activity of HDACs to increase acetylation levels and showed that such a strategy is capable of simultaneously inducing multiple RAGs and promoting axon regeneration after SCI (Fig. 8). The in vivo promoting effect of MS-275 remains modest with the current treatment regimen; however, this may be improved by testing different MS-275 doses or treatment windows, alternative HDACi, or, as discussed earlier, a combinatorial treatment of HDACi and activation of TFs, such as Smad1 by AAV-BMP4.

Our current study cannot rule out the possibility that TSA or MS-275 treatment inhibits the activity of HDACs in deacetylating cytoplasmic proteins, particularly in light of the presence of HDACs in axons (Kim et al., 2010). TSA may inhibit HDAC6, a cytoplasmic HDAC, the inhibition of which can promote neurite outgrowth on nonpermissive substrates independent of transcription, perhaps through deacetylation of cytoplasmic $\alpha$-tubulin (Rivieccio et al., 2009). However, the transcriptional changes observed with TSA or MS-275 treatment in our study and their effects on AcH4 enrichment, both globally and selectively at early RAGs promoters, strongly argue for a major contribution of histone acetylation. Future studies are needed to delineate the function of HDAC isoforms, other histone modification enzymes, and their transcriptional targets during this epigenetic reprogramming. In addition to changes in abundance, enzymatic activity and recruitment of HDACs to specific RAGs promoters may all be subject to regulation in regenerating neurons.

It is also noted that systemic administration of TSA or MS-275 may affect non-neuronal cells, such as glia, which may provide trophic support to promote regeneration. HDACi can induce GDNF and BDNF in astrocytes (Wu et al., 2008), both of which may enhance regeneration of centrally projecting DRG axons. Nonetheless, the following lines of evidence support a strong contribution of neuronal epigenetic reprogramming in the regeneration process: (1) we did not observe differences in glial scar size between MS-275-treated animals and controls; (2) isolated DRG neurons from TSA- or MS275-treated mice exhibited increased intrinsic axon growth potential in dissociated cultures; (3) AcH4 enrichment and pSmad1 nuclear accumulation occurred predominantly in neurons and not glial cells in DRGs after a peripheral axotomy; (4) many of the RAGs studied here, such as Sprrla, Npy, Galanin, and Vip, are neuronal specific (Bonilla et al., 2002; Starkey et al., 2009; Zigmond, 2012); therefore, changes in their expression with MS-275 treatment more likely reflect changes in DRG neurons that contribute to enhanced axon growth potential. Indeed, Sprr1a, when overexpressed, augments axonal outgrowth on a range of substrates (Bonilla et al., 2002); and (5) most of the changes observed in pSmad1 promoter occupancy, AcH4 enrichment, and HDAC/HAT binding, as well as RAG transcriptional changes, were demonstrated in a neuronal cell line, therefore supporting a neuronal cell-autonomous effect. Future studies will determine whether epigenetic reprogramming in non-neuronal cells also contributes to axon regeneration. Additionally, other modalities of epigenetic 
modifications, such as histone or DNA methylation, may also participate in the epigenetic reprogramming. Functions of residue-specific histone acetylation modifications, such as $\mathrm{H} 3 \mathrm{~K} 14, \mathrm{H} 4 \mathrm{~K} 5$, and $\mathrm{H} 4 \mathrm{~K} 12$ in axon regeneration, which have been shown to be important for CNS plasticity (Gräff et al., 2011), also await future investigations.

Collectively, our study provides a platform for exploring epigenetic mechanisms to promote axon regeneration.

\section{References}

Bird A (2007) Perceptions of epigenetics. Nature 447:396-398. CrossRef Medline

Bonilla IE, Tanabe K, Strittmatter SM (2002) Small proline-rich repeat protein $1 \mathrm{~A}$ is expressed by axotomized neurons and promotes axonal outgrowth. J Neurosci 22:1303-1315. Medline

Bosse F, Küry P, Müller HW (2001) Gene expression profiling and molecular aspects in peripheral nerve regeneration. Restor Neurol Neurosci 19: 5-18. Medline

Cao Z, Gao Y, Bryson JB, Hou J, Chaudhry N, Siddiq M, Martinez J, Spencer T, Carmel J, Hart RB, Filbin MT (2006) The cytokine interleukin-6 is sufficient but not necessary to mimic the peripheral conditioning lesion effect on axonal growth. J Neurosci 26:5565-5573. CrossRef Medline

Cafferty WB, Yang SH, Duffy PJ, Li S, Strittmatter SM (2007) Functional axonal regeneration through astrocytic scar genetically modified to digest chondroitin sulfate proteoglycans. J Neurosci 27:2176-2185. CrossRef Medline

Case LC, Tessier-Lavigne M (2005) Regeneration of the adult central nervous system. Curr Biol 15:R749-R753. CrossRef Medline

Costigan M, Befort K, Karchewski L, Griffin RS, D’Urso D, Allchorne A, Sitarski J, Mannion JW, Pratt RE, Woolf CJ (2002) Replicate highdensity rat genome oligonucleotide microarrays reveal hundreds of regulated genes in the dorsal root ganglion after peripheral nerve injury. BMC Neurosci 3:16. CrossRef Medline

Danielian PS, Muccino D, Rowitch DH, Michael SK, McMahon AP (1998) Modification of gene activity in mouse embryos in utero by a tamoxifeninducible form of Cre recombinase. Curr Biol 8:1323-1326. CrossRef Medline

Ernst J, Kheradpour P, Mikkelsen TS, Shoresh N, Ward LD, Epstein CB, Zhang X, Wang L, Issner R, Coyne M, Ku M, Durham T, Kellis M, Bernstein BE (2011) Mapping and analysis of chromatin state dynamics in nine human cell types. Nature 473:43-49. CrossRef Medline

Filbin MT (2003) Myelin-associated inhibitors of axonal regeneration in the adult mammalian CNS. Nat Rev Neurosci 4:703-713. CrossRef Medline

Gaub P, Tedeschi A, Puttagunta R, Nguyen T, Schmandke A, Di Giovanni S (2010) HDAC inhibition promotes neuronal outgrowth and counteracts growth cone collapse through $\mathrm{CBP} / \mathrm{p} 300$ and $\mathrm{P} / \mathrm{CAF}-$ dependent p53 acetylation. Cell Death Differ 17:1392-1408. CrossRef Medline

Gaub P, Joshi Y, Wuttke A, Naumann U, Schnichels S, Heiduschka P, Di Giovanni S (2011) The histone acetyltransferase p300 promotes intrinsic axonal regeneration. Brain 134:2134-2148. CrossRef Medline

Goldberg JL (2003) How does an axon grow? Genes Dev 17:941-958. CrossRef Medline

Gräff J, Kim D, Dobbin MM, Tsai LH (2011) Epigenetic regulation of gene expression in physiological and pathological brain processes. Physiol Rev 91:603-649. CrossRef Medline

Harel NY, Strittmatter SM (2006) Can regenerating axons recapitulate developmental guidance during recovery from spinal cord injury? Nat Rev Neurosci 7:603-616. CrossRef Medline

Huang S, Tang B, Usoskin D, Lechleider RJ Jamin SP, Li C, Anzano MA, Ebendal T, Deng C, Roberts AB (2002) Conditional knockout of the Smad1 gene. Genesis 32:76-79. CrossRef Medline

Iskandar BJ, Rizk E, Meier B, Hariharan N, Bottiglieri T, Finnell RH, Jarrard DF, Banerjee RV, Skene JH, Nelson A, Patel N, Gherasim C, Simon K, Cook TD, Hogan KJ (2010) Folate regulation of axonal regeneration in the rodent central nervous system through DNA methylation. J Clin Invest 120:1603-1616. CrossRef Medline

Jiang Y, Matevossian A, Huang HS, Straubhaar J, Akbarian S (2008) Isolation of neuronal chromatin from brain tissue. BMC Neurosci 9:42. CrossRef Medline

Juergens RA, Vendetti F, Coleman B, Sebree RS, Rudek MA, Belinsky S, Brock M, Herman J, Baylin S, Rudin CM (2009) Interim analysis of a phase II trial of 5-azacitidine (5AC) and entinostat (SNDX-275) in relapsed advanced lung cancer (NSCLC). J Clin Oncol 27.

Jun JH, Yoon WJ, Seo SB, Woo KM, Kim GS, Ryoo HM, Baek JH (2010) BMP2-activated Erk/MAP kinase stabilizes Runx2 by increasing p300 levels and histone acetyltransferase activity. J Biol Chem 285:36410-36419. CrossRef Medline

Kim DW, Lassar AB (2003) Smad-dependent recruitment of a histone deacetylase/sin $3 \mathrm{~A}$ complex modulates the bone morphogenetic proteindependent transcriptional repressor activity of Nkx3.2. Mol Cell Biol 23: 8704-8717. CrossRef Medline

Kim JY, Shen S, Dietz K, He Y, Howell O, Reynolds R, Casaccia P (2010) HDAC1 nuclear export induced by pathological conditions is essential for the onset of axonal damage. Nat Neurosci 13:180-189. CrossRef Medline

Konsoula Z, Barile FA (2012) Epigenetic histone acetylation and deacetylation mechanisms in experimental models of neurodegenerative disorders. J Pharmacol Toxicol Methods 66:215-220. CrossRef Medline

Kouzarides T (2007) Chromatin modifications and their function. Cell 128: 693-705. CrossRef Medline

Kusanagi K, Inoue H, Ishidou Y, Mishima HK, Kawabata M, Miyazono K (2000) Characterization of a bone morphogenetic protein-responsive Smad-binding element. Mol Biol Cell 11:555-565. CrossRef Medline

Lee JK, Geoffroy CG, Chan AF, Tolentino KE, Crawford MJ, Leal MA, Kang B, Zheng B (2010) Assessing spinal axon regeneration and sprouting in Nogo-, MAG-, and OMgp-deficient mice. Neuron 66:663-670. CrossRef Medline

Liu K, Lu Y, Lee JK, Samara R, Willenberg R, Sears-Kraxberger I, Tedeschi A, Park KK, Jin D, Cai B, Xu B, Connolly L, Steward O, Zheng B, He Z (2010) PTEN deletion enhances the regenerative ability of adult corticospinal neurons. Nat Neurosci 13:1075-1081. CrossRef Medline

Lv L, Han X, Sun Y, Wang X, Dong Q (2012) Valproic acid improves locomotion in vivo after SCI and axonal growth of neurons in vitro. Exp Neurol 233:783-790. CrossRef Medline

Minucci S, Pelicci PG (2006) Histone deacetylase inhibitors and the promise of epigenetic (and more) treatments for cancer. Nat Rev Cancer 6:38 51. CrossRef Medline

Morikawa M, Koinuma D, Tsutsumi S, Vasilaki E, Kanki Y, Heldin CH, Aburatani H, Miyazono K (2011) ChIP-seq reveals cell type-specific binding patterns of BMP-specific Smads and a novel binding motif. Nucleic Acids Res 39:8712-8727. CrossRef Medline

Neumann S, WoolfCJ (1999) Regeneration of dorsal column fibers into and beyond the lesion site following adult spinal cord injury. Neuron 23:8391. CrossRef Medline

Nix P, Hisamoto N, Matsumoto K, Bastiani M (2011) Axon regeneration requires coordinate activation of p38 and JNK MAPK pathways. Proc Natl Acad Sci U S A 108:10738-10743. CrossRef Medline

Parikh P, Hao Y, Hosseinkhani M, Patil SB, Huntley GW, Tessier-Lavigne M, Zou H (2011) Regeneration of axons in injured spinal cord by activation of bone morphogenetic protein/Smad1 signaling pathway in adult neurons. Proc Natl Acad Sci U S A 108:E99-E107. CrossRef Medline

Park KK, Liu K, Hu Y, Smith PD, Wang C, Cai B, Xu B, Connolly L, Kramvis I, Sahin M, He Z (2008) Promoting axon regeneration in the adult CNS by modulation of the PTEN/mTOR pathway. Science 322:963-966. CrossRef Medline

Pearson KL, Hunter T, Janknecht R (1999) Activation of Smad1-mediated transcription by p300/CBP. Biochim Biophys Acta 1489:354-364. CrossRef Medline

Peleg S, Sananbenesi F, Zovoilis A, Burkhardt S, Bahari-Javan S, Agis-Balboa RC, Cota P, Wittnam JL, Gogol-Doering A, Opitz L, Salinas-Riester G, Dettenhofer M, Kang H, Farinelli L, Chen W, Fischer A (2010) Altered histone acetylation is associated with age-dependent memory impairment in mice. Science 328:753-756. CrossRef Medline

Ram O, Goren A, Amit I, Shoresh N, Yosef N, Ernst J, Kellis M, Gymrek M, Issner R, Coyne M, Durham T, Zhang X, Donaghey J, Epstein CB, Regev A, Bernstein BE (2011) Combinatorial patterning of chromatin regulators uncovered by genome-wide location analysis in human cells. Cell 147:1628-1639. CrossRef Medline

Richardson PM, Issa VM (1984) Peripheral injury enhances central regeneration of primary sensory neurones. Nature 309:791-793. CrossRef Medline

Rivieccio MA, Brochier C, Willis DE, Walker BA, D'Annibale MA, McLaughlin K, Siddiq A, Kozikowski AP, Jaffrey SR, Twiss JL, Ratan RR, Langley B (2009) HDAC6 is a target for protection and regeneration following in- 
jury in the nervous system. Proc Natl Acad Sci U S A 106:19599-19604. CrossRef Medline

Ross S, Cheung E, Petrakis TG, Howell M, Kraus WL, Hill CS (2006) Smads orchestrate specific histone modifications and chromatin remodeling to activate transcription. EMBO J 25:4490-4502. CrossRef Medline

Saito A, Yamashita T, Mariko Y, Nosaka Y, Tsuchiya K, Ando T, Suzuki T, Tsuruo T, Nakanishi O (1999) A synthetic inhibitor of histone deacetylase, MS-27-275, with marked in vivo antitumor activity against human tumors. Proc Natl Acad Sci U S A 96:4592-4597. CrossRef Medline

Schwab ME, Bartholdi D (1996) Degeneration and regeneration of axons in the lesioned spinal cord. Physiol Rev 76:319-370. Medline

Shin JE, Cho Y, Beirowski B, Milbrandt J, Cavalli V, DiAntonio A (2012) Dual leucine zipper kinase is required for retrograde injury signaling and axonal regeneration. Neuron 74:1015-1022. CrossRef Medline

Skene JH (1989) Axonal growth-associated proteins. Annu Rev Neurosci 12:127-156. CrossRef Medline

Smith DS, Skene JH (1997) A transcription-dependent switch controls competence of adult neurons for distinct modes of axon growth. J Neurosci 17:646-658. Medline

Starkey ML, Davies M, Yip PK, Carter LM, Wong DJ, McMahon SB, Bradbury EJ (2009) Expression of the regeneration-associated protein SPRR1A in primary sensory neurons and spinal cord of the adult mouse following peripheral and central injury. J Comp Neurol 513:51-68. CrossRef Medline

Sun F, Park KK, Belin S, Wang D, Lu T, Chen G, Zhang K, Yeung C, Feng G, Yankner BA, He Z (2011) Sustained axon regeneration induced by codeletion of PTEN and SOCS3. Nature 480:372-375. CrossRef Medline

Tedeschi A, Nguyen T, Puttagunta R, Gaub P, Di Giovanni S (2009) A p53$\mathrm{CBP} / \mathrm{p} 300$ transcription module is required for GAP-43 expression, axon outgrowth, and regeneration. Cell Death Differ 16:543-554. Medline
Tedeschi A (2012) Tuning the orchestra: transcriptional pathways controlling axon regeneration. Front Mol Neurosci 4:60. CrossRef Medline

Trakhtenberg EF, Goldberg JL (2012) Epigenetic regulation of axon and dendrite growth. Front Mol Neurosci 5:24. CrossRef Medline

van Kesteren RE, Mason MR, Macgillavry HD, Smit AB, Verhaagen J (2011) A gene network perspective on axonal regeneration. Front Mol Neurosci 4:46. CrossRef Medline

Wu X, Chen PS, Dallas S, Wilson B, Block ML, Wang CC, Kinyamu H, Lu N, Gao X, Leng Y, Chuang DM, Zhang W, Lu RB, Hong JS (2008) Histone deacetylase inhibitors up-regulate astrocyte GDNF and BDNF gene transcription and protect dopaminergic neurons. Int J Neuropsychopharmacol 11:1123-1134. CrossRef Medline

Xiao HS, Huang QH, Zhang FX, Bao L, Lu YJ, Guo C, Yang L, Huang WJ, Fu G, Xu SH, Cheng XP, Yan Q, Zhu ZD, Zhang X, Chen Z, Han ZG, Zhang $X$ (2002) Identification of gene expression profile of dorsal root ganglion in the rat peripheral axotomy model of neuropathic pain. Proc Natl Acad Sci U S A 99:8360-8365. CrossRef Medline

Ylera B, Ertürk A, Hellal F, Nadrigny F, Hurtado A, Tahirovic S, Oudega M, Kirchhoff F, Bradke F (2009) Chronically CNS-injured adult sensory neurons gain regenerative competence upon a lesion of their peripheral axon. Curr Biol 19:930-936. CrossRef Medline

Zhou FQ, Snider WD (2006) Intracellular control of developmental and regenerative axon growth. Philos Trans R Soc Lond B Biol Sci 361:15751592. CrossRef Medline

Zigmond RE (2012) gp130 cytokines are positive signals triggering changes in gene expression and axon outgrowth in peripheral neurons following injury. Front Mol Neurosci 4:62. CrossRef Medline

Zou H, Ho C, Wong K, Tessier-Lavigne M (2009) Axotomy-induced Smad1 activation promotes axonal growth in adult sensory neurons. J Neurosci 29:7116-7123. CrossRef Medline 